IZA DP No. 5692

The Determinants of Poverty Transitions in Europe and the Role of Duration Dependence

Eirini Andriopoulou

Panos Tsakloglou

May 2011 


\title{
The Determinants of Poverty Transitions in Europe and the Role of Duration Dependence
}

\author{
Eirini Andriopoulou \\ Athens University of Economics and Business \\ Panos Tsakloglou \\ Athens University of Economics and Business \\ and IZA
}
Discussion Paper No. 5692
May 2011

IZA

P.O. Box 7240

53072 Bonn

Germany

Phone: +49-228-3894-0

Fax: +49-228-3894-180

E-mail: iza@iza.org

Any opinions expressed here are those of the author(s) and not those of IZA. Research published in this series may include views on policy, but the institute itself takes no institutional policy positions.

The Institute for the Study of Labor (IZA) in Bonn is a local and virtual international research center and a place of communication between science, politics and business. IZA is an independent nonprofit organization supported by Deutsche Post Foundation. The center is associated with the University of Bonn and offers a stimulating research environment through its international network, workshops and conferences, data service, project support, research visits and doctoral program. IZA engages in (i) original and internationally competitive research in all fields of labor economics, (ii) development of policy concepts, and (iii) dissemination of research results and concepts to the interested public.

IZA Discussion Papers often represent preliminary work and are circulated to encourage discussion. Citation of such a paper should account for its provisional character. A revised version may be available directly from the author. 


\section{ABSTRACT \\ The Determinants of Poverty Transitions in Europe and the Role of Duration Dependence}

The paper examines the mobility into and out of poverty and identifies the determinants of poverty spell beginnings and endings in 14 European Countries for the period 1994-2000, using the European Community Household Panel. The first part of the paper offers a snapshot of poverty mobility in Europe calculating the entry and exit poverty rates, along with the conditional, to the duration of spell, exit probabilities and re-entry rates to poverty. In the second part observed characteristics of the household and the household head are examined in order to identify the determinants of the transitions into and out of poverty, taking into account unobserved heterogeneity across individuals and duration dependence. Multivariate discrete hazard analysis is used and the duration dependence is captured with time dummies. In almost all the 14 EU Member-States examined, the probability of exiting (re-entering) poverty is inversely related to the duration of the poverty (non-poverty) spell. The effect is significant to the inclusion of variables capturing observed heterogeneity (socioeconomic characteristics of the household head and the household and particular employment and demographic events), as well as to the inclusion of a random effects factor capturing the unobserved heterogeneity across individuals. With regards to the socioeconomic variables, in most countries, households headed by young or elderly individuals, as well as households with dependent children are in higher risk of staying longer in poverty. In many cases, event variables improve the model significantly and highlight the mechanisms that bring individuals into and out of poverty.

JEL Classification: $\quad$ I32, I38

Keywords: $\quad$ poverty dynamics, EU

Corresponding author:

Panos Tsakloglou

Athens University of Economics and Business

76 Patission Street

Athens 10434

Greece

E-mail:panos@aueb.gr 


\section{INTRODUCTION}

Traditionally, social scientists have studied poverty in a static way. Yet, the examination of the poverty level at one point in time does not offer a sufficiently complete picture of this social phenomenon, as it ignores the dimension of time, which may be particularly important for the proper design and implementation of poverty alleviating policies. For instance, the group of poor persons observed at one point in time may consist of individuals who have experienced poverty in the past or individuals that experience poverty for first time. "Are the poor this year the same people who were poor last year?" is an important question that needs to be answered. In this paper we initially seek to answer "how transitory is poverty, what is the percentage of permanent poverty and how recurrent poverty might be?" The way to answer these questions is to use dynamic analysis techniques, which study the determinants of poverty incidence, transition and persistence.

One very popular way to study poverty dynamics is through individuals' poverty spells. Duncan (1984) studied first the persistence of poverty using tabulations of the frequency of the poverty event over some fixed time frame. An extension to this analysis is the work of Bane and Ellwood (1986), who introduced spell durations and exit probabilities in the analysis of poverty. They defined the poverty spell to be "continuous periods during which income falls below the poverty line" (p. 6) and, thus, the beginning of a poverty spell to be the first year that the income is below the poverty line and its ending to be the year when income is above the poverty line after having been continuously below it. In this way, the total period of survey for each individual is divided into smaller periods (spells into and out of poverty).

What is particularly interesting about spells' methodology is that it offers an overall picture e.g. of permanent poverty, through the examination of individual poverty experiences. Nevertheless, for the application of this method, information on the same individuals and households over several years, or in other words, a pure panel data structure, is necessary. Such surveys at large scale are very costly and hard to maintain in terms of number of individuals and households. The European Community Household Panel is the first pure panel dataset, which includes all the EU-15 Member-States ${ }^{1}$. In the ECHP, poverty spells can be constructed at an annual basis, since income information was collected once a year and had an annual reference period $^{2}$. These annual spells are a proxy to the true experience of poverty, since income may fluctuate significantly between the yearly interviews of the panel survey.

Some of the most important poverty studies using spell techniques are done using the US Panel Study on Income Dynamics (PSID) ${ }^{3}$ which was launched in 1968 and has now almost 40 waves available for panel analysis. Bane and Ellwood (1986) were the pioneers in this kind of analysis. Their main finding for the period 1970-1982 in the US was that while most of those who fall into poverty exit poverty quickly, the bulk of those poor in a particular period are in the midst of a long poverty spell. Duncan et al. (1993) performed the first comparative analysis, studying poverty dynamics in eight countries (US, Canada, France, Germany, the Netherlands, Luxembourg, Ireland and Sweden) and found extensive mobility among the poor in all countries under examination. When studying poverty across Canada, Germany, the Netherlands, Sweden, the United Kingdom and the United States, Oxley et al. (2000) found that the majority of the poor have short spells in poverty and that as spells lengthen, the probability of exit falls such that a small group of the population remains in poverty for long periods of time with little chance of exit. In most cases, low probability of exit is combined with high probability of reentry.

\footnotetext{
${ }^{1}$ Apart from Sweden, for which only cross-sectional data are available for this period.

2 Monthly income data are also available in the ECHP, but they are prone to underreporting, and to temporary fluctuations. Thus, it might not be appropriate to characterize an individual as "poor" or "non-poor" on a monthly basis. Yet, for other types of spells e.g. unemployment spells, the monthly division might be more appropriate.

${ }^{3}$ Ruggles and Williams (1986) do similar analysis using data from the Survey of Income Participation.
} 
Stevens (1994) was the first to analyse multiple or repeated spells by examining the duration of subsequent non-poverty spells. Her results for the US for the period 1970-1987 indicate that more than half of the individuals that escape poverty re-enter within the first five years. In similar studies, in Canada, for the period 1992-1996, Finnie (2000) found that those who are permanently poor (all five years) constitute $6 \%$ of the population, and at the same time they represent on average $40 \%$ of the poor population in any given year.

In European countries, studies using poverty spell analysis are not as numerous as in the US due to the lack of appropriate data in all the EU countries. Important studies have been developed using the British Household Panel Survey (BHPS). With respect to the poverty prevalence, Jarvis and Jenkins (1997) estimated that at least one third of the British population experiences low income at least once during the four year period that they examined. In a subsequent study, Jenkins (2000) reported that one-fifth of the individuals leaving poverty in the period 1991-1996 in the UK had another poverty spell in the next five years. Jenkins et al. (2001) using also the BHPS concluded that one in seven individuals were poor at three or four years out of four during the 1990s, while one third of the population were poor at least for one year out of four. Regarding the length of poverty spells, $46 \%$ of all poor individuals in the observation period leave poverty after one year, but at the same time more that $12 \%$ remain poor for at least five years. Moreover, $30 \%$ of those that exit poverty re-enter poverty after just one year. Re-entry into poverty turns out to be an important risk also in Belgium, even after several years spent out of poverty (Van Kerm 2002, 2004). Canto (2003) also found that there is a lot of mobility around the poverty line in Spain, but of a small range, meaning that the incomes of the poor fluctuate around the poverty line, making them vulnerable to poverty reentries.

In line with the above studies, in the first part of this paper, we use poverty spells methodology in order to examine what is the duration and recurrence of poverty in Europe and whether it varies across Member-States. To our knowledge, this is the first comparative study that examines poverty dynamics in so many EU Member-States at the same time. In order to answer the above question, we first examine four "poverty profiles" based on the Muffels et al. (2000) typology used also by Fouarge and Layte (2005). Then, we calculate the entry and exit poverty rates, along with the conditional, to the duration of spell, exit probabilities and re-entry rates to poverty.

In the second part of the paper, the effect of time on poverty transitions is examined in an econometric framework along with various time-constant and time-varying variables (including event variables) that are usually considered as the determinants of poverty entries and exits. The main question to be answered is still whether and to what extent the duration of the poverty (non-poverty) spell affects the probability of exiting (re-entering) poverty. At the same time the socioeconomic characteristics of poor individuals and households are also identified.

The bulk of the literature on the role of time on poverty asserts that there is a negative effect of time on the probability of exiting or re-entering poverty. According to Heckman (1981), true state dependence ${ }^{4}$ means that the experience of poverty in one year per se raises the risk of being poor in the next year. However, the duration dependence observed in data may also be attributed, at least partly, to sorting effects (individuals with "favourable" characteristics tend to leave poverty earlier) rather than indicating true state dependence e.g. due to the depreciation of human capital (Poggi 2007). In the same way, the group of people that remain longer into poverty may possess certain characteristics (observable or unobservable) that obstruct the end of the poverty spell and, thus, poverty may be unrelated to the duration of the poverty spell. If this is the case, the relationship observed between poverty duration and exit probability is spurious

\footnotetext{
${ }^{4}$ Precisely, the term "state dependence" is used in order to define the dependence of the status (poverty or nonpoverty) in $t$ on the status of the dependent variable in $t-1$, while the term "duration dependence", expresses the dependence of the status (poverty or non-poverty) in $t$ on the duration spent in this status. Yet, the two terms are often used as synonyms in the literature. In this paper we focus on duration dependence but, indirectly, state dependence is also examined.
} 
and indirectly reflects other causalities. Many papers report that a significant part of this duration dependence is artificial and can be attributed to unobserved differences among individuals than to the effect of time per se. Thus, the econometric model that we develop takes into account the effect of unobserved heterogeneity.

In the last decade, researchers consistently try to distinguish between true state or duration dependence and individual heterogeneity. Most studies conclude that poverty state dependence remains significant even when controlling for unobserved heterogeneity. Canto (1996) examined the duration dependence for poverty entries and exits in Spain using a nonparametric specification for the hazard rate. She controlled for unobserved heterogeneity indirectly by testing the homogeneity of the hazard rate between groups which are likely to have different spell lengths. She finds significant duration dependence both for poverty re-entries and exits. Cappellari and Jenkins (2004) using data from the BHPS for the 1990s concluded that there is substantial state dependence in poverty, separately from the persistence caused by heterogeneity. Biewen $(2003 ; 2006)$ reports that even after controlling for observed and unobserved individual characteristics, there is negative duration dependence in poverty exit and re-entry behaviour. He also calculates that $6 \%$ of the German population has unobserved characteristics that lead to low poverty exit and high re-entry rates, therefore making these individuals possible candidates for chronic poverty. Poggi (2007) studies social exclusion dynamics in Spain and also finds that both individual heterogeneity and true state dependence are related to the probability of experiencing social exclusion.

It is logical to assume that the unobserved characteristics that affect the probability of exit may also affect the probability of entry. For instance "more able" individuals are more likely to exit poverty quickly and also less likely to re-enter poverty. This case raises arguments for modeling jointly poverty entries and exits and therefore accounting for multiple spells (Ondrich and Rhody 1999; Stevens 1999; Jenkins et al. 2001; Devicienti 2002; Hansen and Wahlberg 2004; Biewen 2006). Stevens (1999) was the first to raise the importance of taking into account multiple spells (both exits and re-entries) when examining the persistent of poverty. She did this by estimating two sets of hazard rates for movements into and out of poverty, controlling for observable characteristics as well as for unobserved heterogeneity. Nevertheless, the key issue for performing multiple spell analysis is the time-frame, which was more than 20 years in her analysis. Devicienti (2002) uses discrete-time proportional hazard models to estimate exit and re-entry rates controlling for various fixed and time-varying covariates. Then, he uses the estimates from the two separate models to forecast poverty persistence over multiple spells for different groups of the population ${ }^{5}$. The trade-off for using multiple-spell analysis with few years of analysis is that he does not control for unobserved heterogeneity. Moreover, Biewen (2006, p. 40) observed that when using a single spell approach the predicted poverty duration is much lower than it is in the sample. Yet, he also found that the multiple spell approach overestimates the probability of the number of years spent in poverty. Using the methodology of Allison (1982), Willett and Singer (1995), Kelly and Lim (2000), Callens and Croux (2009) employ a class of recurrent hazard models so as to model the case of multiple spells separately for women and men. Finally, a recent paper by Damioli (2010) specifies separate identical exit and re-entry hazard models for each country and in parallel uses the Oaxaca-Blinder decomposition that allows the disentangling of crosscountry differences in measures of poverty dynamics and attributes the differences of exit and re-entry rates across countries to differences in the composition of the population and the poverty dynamics generating process per se. In this paper, given that the ECHP observation

\footnotetext{
${ }^{5}$ In order to derive the distribution of time spent poor over multiple spells Devicienti (2002) combines the estimates of exit and re-entry rates. Specifically, he calculates the probability of observing a certain income sequence (e.g. poor, non-poor, poor, poor, poor, non-poor) as the product of the probability of constituent spells. Then, he computes the probabilities of all possible sequences that give e.g. a total of four years in poverty.
} 
period is only eight years ${ }^{6}$, in combination with the fact that we want to control for unobserved heterogeneity, we model separately poverty entries and exits.

\section{THE MODEL}

Jenkins (2000) distinguishes between four main types of multivariate models used in income and poverty dynamics research: the longitudinal poverty pattern models, transition probability models, income variance component models and structural models.

Longitudinal poverty pattern models model the probability of observing a specific "longitudinal poverty sequence" e.g. being poor for six years controlling only for fixed characteristics (see Gardiner and Hills 1999; Hill and Jenkins 1999). Such models have been used more for producing measures of "permanent" income or "chronic poverty" than studying poverty dynamics in terms of transitions.

The transition probability models are the most commonly used in the literature of poverty dynamics and belong to the category of the discrete multivariate hazard rate or duration models. Transition probability models are in practice a generalization of life-tables, allowing transition rates to vary not only with time but also with selected personal and household characteristics (Jenkins et al. 2001, p. 70). The dependent variable in these models is the probability of exiting, entering or re-entering poverty and the explanatory variables may describe time duration, observed individual and household characteristics, as well as unobserved heterogeneity. These models differ with regard to the specification of the explanatory variables used. The model used in this paper for performing the econometric analysis belongs to this category.

Another method for studying poverty dynamics, which originates mainly from the study of income dynamics and earnings mobility is the estimation of components of variance models to describe the evolution of income or earnings over time (Lillard and Willis 1978; Abowd and Card 1989; Duncan and Rodgers 1991; Stevens 1999). Yet, predictions using this method are less consistent with the patterns of poverty dynamics derived from hazard models, probably because they are based on parameters describing the full distribution of income, while the hazard rate models focus on samples of individuals below the poverty line (see Stevens 1999, p. 582-583).

The most recently used models are the structural models, introduced by Burgess and Propper (1998) and extended later by Aassve et al. (2006a; 2006b). The authors first model the probability of having certain outcomes of marital status, fertility and labour force participation, then, estimate the earnings associated with different combinations of outcomes and, finally, predict poverty status. The predicted poverty rates seem to match the real poverty rates very well. The authors use a simple economic behavioural model for estimating the economic processes that determine poverty. Yet, as they point out, other models can also be used (Burgess and Propper 1998, p. 54). Jenkins (2000) characterizes these models as innovative, but very hard and time-consuming to develop.

When applying "duration", "survival" or "hazard" analysis the key issue to study is the hazard rate, which is defined as the probability of experiencing the "event" (exit/entry poverty) after a certain number of years conditional on not having experience of the event up to that time. In this way, it is obvious that the hazard rates are simply conditional probabilities, which depend on how long the spell has been in progress and are calculated using only the population that is still at-risk of experiencing the event (Jenkins et al. 2001). Since, the event of interest (poverty exit or re-entry) may occur at any time, but the data are available yearly (in discrete time intervals), a discrete-time hazard model is more appropriate than a continuous-time hazard model (Jenkins 2004). In particular, the model that we estimate is the discrete time hazard

\footnotetext{
${ }^{6}$ The eight year panel practically ends to a five year observation period for two reasons: first, we lag the household income in order to timely match the socioeconomic variables with the income variables, and, second, we exclude left censored cases.
} 
model, in which the dependent variable is the logit ${ }^{7}$ transformation of the hazard rate $h_{i d}$ for each person $i$ for the spell year $d$ :

$$
\operatorname{logit}\left(h_{i d}\right)=\log \left(\frac{h_{i d}}{1-h_{i d}}\right)=f(d)+\beta^{\prime} X_{i d}
$$

which is equivalent to:

$$
h_{i d}=\frac{1}{1+\exp \left(-f(d)-\beta^{\prime} X_{i d}\right)}
$$

where $f(d)=a_{1 i} d_{1}+a_{2 i} d_{2}+a_{3 i} d_{3}+a_{4 i} d_{4}+a_{5 i} d_{5}$ is the baseline hazard in a non-parametric specification form (with year-specific dummy variables), $X_{i d}$ the vector of household characteristics for each person $i$ for the spell year $d$. These explanatory variables may be timeconstant or time-varying. $\beta^{\prime}$ is the vector of the regression coefficients associated with the exogenous variables. If the coefficient has a positive sign, then increases in the value of the variable are associated with a larger hazard rate and shorter spells, other things being equal, and vice versa. As a conditional probability, the value of the hazard must lie between 0 and 1 .

Since we control for unobserved heterogeneity or frailty, an individual-specific unobserved characteristic $u$ is added. $u$ follows a given parametric distribution ${ }^{8}$ (gamma or normal $\left.{ }^{9}\right)$.

$$
\operatorname{logit}\left(h_{i d}\right)=\log \left(\frac{h_{i d}}{1-h_{i d}}\right)=f(d)+\beta^{\prime} X_{i d}+u
$$

We have estimated $u$ using random effect techniques, since the random-effects approach leads to more efficient estimators compared to fixed effects if the distributional assumptions are satisfied and allows for easy calculation of predictions (see Honore 2002 for a full discussion on the issue).

In the specification presented in this paper, we also use event variables to capture certain employment or demographic changes that happen to the household, thus the model is changing into the following:

$$
\operatorname{logit}\left(h_{i d}\right)=\log \left(\frac{h_{i d}}{1-h_{i d}}\right)=f(d)+\beta^{\prime} X_{i d}+\gamma^{\prime} E_{i d} \text { or } \operatorname{logit}\left(h_{i d}\right)=\log \left(\frac{h_{i d}}{1-h_{i d}}\right)=f(d)+\beta^{\prime} X_{i d}+\gamma^{\prime} E_{i d}+u
$$

There is much controversy in the literature on whether multivariate models should include event (transition) variables as covariates or only "state variables" which may be both time-constant or time-varying. Many researchers find that event variables in logit regressions are significant even when controlling for the corresponding state variable (Antolin et al. 1999; Muffels et al. 2000; Muffels 2000; Oxley et al. 2000; Van Leeuwen and Pannekoek 2002; Finnie and Sweetman 2003; Dewilde 2004). On the contrary Canto (2003), following Jenkins and Schluter (2003) avoids using event variables in the logit regression for the possibility of the endogeneity problem. Another question highlighted by Jenkins (2000) related to the inclusion of event variables to hazard models, is "for how long the effect of an event will be turned on?" For instance if an unemployment event occurs at period $t$ then the relevant dummy will take the

\footnotetext{
7 The complementary $\log \log$ specification is also often used: $c \log \log \left(h_{i d}\right)=f(d)+\beta^{\prime} X_{i d}$, which is equivalent to $\log \left(-\log \left(1-\left(h_{i d}\right)\right)=f(d)+\beta^{\prime} X_{i d}\right.$ or $h_{i d}=1-\exp \left(-\exp \left(f(d)+\beta^{\prime} X_{i d}\right)\right)$. The main difference between a discrete-time hazard model based on a cloglog and one based on a logit transformation is that the cloglog model assumes proportional hazards, while the logit model assumes proportional odds (Singer and Willett 2003; Jenkins 2004). As Allison (1982) and Jenkins $(1997,2004)$ note, the complementary log-log model can be interpreted as the discretetime counterpart of an underlying continuous-time proportional hazard model. We have also tried to use the cloglog specification, but the model did not converge for many countries.

${ }^{8}$ The specification for unobserved heterogeneity can also be fully non-parametric by using one or multiple mass points, following Heckman and Singer (1984). For a recent application on poverty dynamics see (Devicienti et al. 2010).

${ }^{9}$ We have run the model assuming both normal and gamma distribution for unobserved heterogeneity. However, the latter did not converge in many countries, so we present only the results of the former.
} 
value of 1 for that period. What about the next period then? Should the dummy return back to the value of 0 ? Given that in most EU Member-States an unemployment benefit exists, the effect of an unemployment event may result in entering poverty one or two years later. Therefore, many analysts suggest that in the case of hazard models which study particularly the effect of time on poverty entries and exits, the event variables do not fit so well into the model if we cannot assume that the effects are entirely contemporaneous. When examining the effect of demographic, employment and health events in the US using the Survey of Income and Programme Participation (SIPP), McKernan and Ratcliff (2005) use not only event variables but also lagged event variables in their discrete-time multivariate model. In this way, they tackle the problem that the effect of an event may not occur immediately.

However, not enough empirical evidence exists to support the above assumptions and there is a series of papers that have incorporated successfully event variables into hazard models. We have performed the analysis using two specifications with and without event variables, so as to test the validity of the above hypothesis. Yet, event variables seem to be significant determinants of transitions into and out of poverty and, therefore, we have decided to include them in the final version of our model. When we include event variables, we exclude the state variables which may lead to simultaneity bias or multicollinearity. Nevertheless, we do not include event variables that capture changes in income (e.g. "change in individuals' income", "change in old age / survivor benefits", "change in sickness / invalidity benefits"), but only demographic and labour market events. Given that the value of the dependent variable "poverty exit" or "poverty entry" depends on the equivalised household income in comparison to the poverty line and the above variables are components of the household income, their inclusion in the model as regressors may indeed cause endogeneity bias.

Since the survival analysis of poverty at discrete time is based on spell analysis, it suffers from left and right censoring, meaning that certain spells start before and finish after the period of our study. At the current framework of analysis, left-censoring cannot be easily taken into account. Therefore, we use only the spells that start within the observation period. In other words, we use only the flow sample of interest ${ }^{10}$. Specifically, for poverty exits, we demand that the individual is non-poor in the first period, poor in the second period and from the third period, we observe whether and when he/she exits poverty. Respectively, the poverty entries are practically poverty re-entries because we need the individual to be poor in the first period, exit poverty in the second period and from the third period and on, we study whether he re-enters poverty and when ${ }^{11}$. The limited number of waves available does not allow to experiment with left-censoring for examining the accuracy of data. Stevens (1999, p. 572) uses the period 19671988 of the PSID. Initially in her study she excludes the left-censored cases, then in a second step she censors the sample at 1973 and uses all spells (censored and non-censored) from 1973 and onwards. She finds no differences in the results concerning poverty persistence, exit and entry rates. If a spell does not end within the observation period then it is right-censored. Individuals with right-censored spells are included in the analysis and they contribute to the calculation of the relevant probability for as long as they stay in the sample. According to Stevens (1999) and Jenkins et al. (2001), this is the "trick" by which censored data are incorporated in the model in a proper way.

\footnotetext{
${ }^{10}$ When analysing poverty transitions, the data used are not a random sample of the population, but are derived from a sample of people flowing into or out of a particular state (flow sampling) or from a sample of those occupying a state at a given time (stock sampling) (Jenkins 1995).

${ }^{11}$ In terms of waves used, the observation period can include up to five waves. As the European Community Household Panel includes eight waves and we have lagged the income back one wave to match it with the household and personal characteristics, we can use only seven waves for hazard analysis. From the seven waves, the first two are used to construct the "inflow" condition; consequently up to five waves can be used for observing poverty exits and re-entries. Yet, since we use the unbalanced sample, the length of the observation period for each individual varies. For example someone may enter the panel in wave 4 as non-poor, being poor in wave 5 and, thus, having an observation period of only two years (waves 7 and 8 ).
} 
Finally, since the panel includes repeated observations of the same individual and his/her same family, the problem of possible violation of the homoskedasticity assumption is present. Therefore, we use the "robust" or "sandwich" estimators for the standard errors, which allow observations to be dependent within cluster, although they must be independent between clusters (see Huber 1967; White 1980).

\section{THE EUROPEAN COMMUNITY HOUSEHOLD PANEL}

The analysis of the current paper is based on the data of the European Community Household Panel (ECHP) produced by the Living Conditions Unit (E-2) of the Social and Regional Statistics and Geographical Information System Directorate (E) of EUROSTAT in Luxembourg. The European Community Household Panel (ECHP) can be defined as a harmonized cross-national longitudinal survey, which focuses on income and living conditions of households and individuals in the European Union. Due to its multidimensional nature, the ECHP provides information at the micro-level across countries and across time on: income, employment, health, education, housing, migration, social transfers and social participation, as well as demographics. In other words, as Eurostat describes it, the ECHP offers data on EU social dynamics (Eurostat 2003b). The duration of the survey is eight years, thus the ECHP consists of eight waves, one for each year, from 1994 to 2001. The ECHP covers all the 15 Member-States of the EU in that period, but not all countries have participated in all waves. In addition some Member-States as the UK and Germany used data from existing panel surveys and converted them to ECHP format. In the current paper, we use all eight waves of the ECHP for $14 \mathrm{EU}$ Member-States ${ }^{12}$.

Most of the income components in the ECHP have an annual time frame of the calendar year preceding the interview. In all ECHP countries, apart from the UK, the calendar year coincides with the tax year, which is the reference period for the income components. Although, in this way income comparability is ensured, other variables like the household composition variables, the economic activity status etc. refer to the time of interview and might not relate well to income measured over a period up to twelve months in the past (Eurostat 2001). This is particularly undesirable for poverty dynamic analysis that tries to identify changes in income components and also uses the lag poverty status as an explanatory variable. Therefore, for the needs of the dynamic analysis that follows, we have reconstructed the household income, transferring all income components one year back ${ }^{13}$.

Following the practice of Eurostat, the poverty line used in the current thesis is set at $60 \%$ of the national median equivalised household income per capita, as it has been calculated using the modified OECD scale which assigns 1 to the first adult, 0.5 to the next adults and 0.3 to children.

\section{SPELL ANALYSIS OF POVERTY TRANSITIONS}

Researchers usually compare the average cross-sectional poverty rate for a certain period with the prevalence poverty rate, in order to easily investigate whether the composition of poor changes over time. The prevalence poverty rate measures the proportion of individuals that experience poverty at least once in the whole survey period to the total population. If the prevalence of poverty over time is low and equals the cross-sectional poverty rate, then income mobility is low and the same individuals remain poor in all waves. If poverty is experienced in

\footnotetext{
${ }^{12}$ For Sweden only cross-sectional data are available; therefore, Sweden has been excluded from the analysis.

${ }^{13}$ It should be underlined that we do not simply lag one wave back the total net household income, but we take into account the different composition that each household might had in the previous wave. The methodology developed for the reconstruction of household income follows the logic of Eurostat's (2003a) construction of household income variable and is similar to the one applied by Debels and Vandecasteele (2008). The algorithm for the reconstruction of household income is available from the authors on request.
} 
short period by a larger proportion of the population (high prevalence poverty rate), then the probability of being poor is more equally shared (Fouarge 2004).

Table 1 reveals that in all countries the prevalence of poverty rate is almost twice as high as the headcount ratio (see column 4). This is a first indication that mobility exists and that for a substantial proportion of the population poverty is a transient situation. Greece and the UK have the highest prevalence poverty rates: Over $42 \%$ of the population in these countries experiences poverty for at least one year in the period of survey. On the contrary, in Finland almost $80 \%$ of the country's population does not experience poverty in the period of survey. Yet, the period of survey is five years for Finland, thus the figure is not comparable with the results for other countries. The same holds for Luxembourg and Austria. From the countries, which have a seven-year participation in the panel, the Netherlands has the lowest prevalence poverty rate, as well as the lowest poverty rate, with only $23.8 \%$ of the total population experiencing poverty in the seven-year period of survey. When comparing the prevelance of poverty rate to the average headcount measure (column 4), the highest ratio appears in Denmark (2.46) followed by Germany (2.35), while the lowest in Portugal (1.87) and Luxembourg (1.87).

When analysing poverty spells, apart from examining poverty prevalence, it is also essential to examine duration. One way to examine poverty duration is to focus on the duration of the longest spell in poverty for the individuals that experience poverty at least once in the years of the survey. Table 2A shows that in all countries (except Italy and Portugal) $45 \%$ of the longest poverty spells observed for each individual in the seven years of survey (1994-2000) last only one year. Denmark and the Netherlands have the highest proportion of one-year spells, as well as the lowest proportion of spells lasting more than six years. Portugal and Greece have the highest percentage of spells longer than six years: $8.8 \%$ and $7.7 \%$, respectively. Another way to examine poverty duration is to calculate the percentage of individuals who experience a certain number of years in poverty for the whole examination period. Practically, this means adding the duration of all poverty spells that an individual may experience in the survey period and produce a total figure. The results for this poverty duration index are presented in Table $2 \mathrm{~B}$. In most countries, they are diminishing as the duration in poverty increases, with the exception of the longest duration for Austria, France, Greece, Luxembourg and Portugal. Especially for Portugal and Greece, the proportion of the poor staying in poverty more than seven years $(9.3 \%$ and $8.2 \%$ ) is greater than the proportion of poor who remain in poverty for both six and even for five years. For Italy the results are in accordance with the findings of Devicienti et al. (2010).

High prevalence of poverty rates combined with short poverty spells could be attributed to the fact that the same individuals might escape and re-enter poverty from year to year and in a way "exchange" position under and over the poverty line. Therefore, it is important to take, also, into account the extent to which poverty is recurrent. Ceteris paribus, recurrence is inversely related to poverty prevalence. The lower the share of recurrent poverty, the higher the prevalence should be. Yet, multiple spells of poverty increase the total duration during which an individual is under the poverty line in a specific period. Thus, even if each spell may have a short duration, in total, the number of years spent in poverty is high.

Duncan et al. (1993) point out that the static dichotomy of poor versus non-poor may be misleading and needs to be replaced by at least four dynamic categories of economic position: the long-term (persistent) poor, the transitory poor, the economically vulnerable and the financially secure. By developing a modification of the poverty profiles typology of Muffels et al. (2000), in Table 3A, we combine in four poverty profiles the three notions of poverty prevalence, duration and recurrence. The first profile "transient poor", includes all those experiencing poverty only once and for only one year. The second profile "mid-term poor" includes the individuals that experience poverty only once but for a period of two years. The "recurrent poor" are defined as those who have been poor more than once but never longer than two consecutive years and finally the "long-term poor" are those who are continuously poor for a period of at least three years. In most countries, the proportion of the transient poor is larger than the other categories, with the exception of Portugal and Greece, where the long-term (or persistent) poor are the majority (39.4\% and $35.0 \%$, respectively), and in Italy, where the 
difference is very small $(35.7 \%$ transient poverty and $34.8 \%$ permanent poverty). The highest proportion of transient poor is found in countries with low poverty rates: Denmark, Finland and the Netherlands. From all countries that have an average headcount ratio for this period over $18 \%$ (see Table 1), Greece and Portugal have the lowest proportion of transient poor to the poor population. Thus, $65 \%$ of the poor in these countries, experience poverty for more than one year. Finland has the highest percentage of two-year poverty, but it has the lowest percentage of recurrent and permanent poor (further, since only five waves of the ECHP are available for Finland, this is likely to bias the corresponding results for recurrent and permanent poverty). The same holds for Luxembourg and Austria, which have very low rates of recurrent and permanent poverty. The problem of multiple spells (recurrent poverty) seems to be more important in Spain, Greece and Italy. Particularly in Spain, the corresponding percentage is 3\% more than the other two countries; thus, while Spain has a low mid-term and a relatively low percentage of persistent poverty, the proportion of individuals "ever poor" who return to poverty, after being non-poor for one or more years, is high. Almost $29 \%$ of the poor in the EU, experience a poverty spell lasting more than 2 years (long-term poor). This corresponds to almost $10 \%$ of the total population (see Table 3B). Apart from Portugal, Greece, Italy, Ireland and the UK that have high proportions of persistent poverty as well as high poverty rates, Luxembourg and France also "suffer" from high figures of permanent poverty (around 30\%), which correspond to almost 7\% of the total population in Luxembourg and 9.5\% in France (see Table 3B). Table 3B actually reveals that the EU-14 countries differ widely in the extent of poverty persistence with the Southern European countries, Ireland and the UK showing high rates, particularly when compared to countries such as Denmark, Finland and the Netherlands. Similar results are found by Layte and Whelan (2003), when analysing poverty persistence using the first five waves of the ECHP.

The unconditional entry and exit rates into and out of poverty simply measure the probability of escaping/entering poverty in $t$, while being poor/non-poor in $t$ - 1 . For the calculation of these probabilities, all spells observed for waves 1-7 are taken into account, including the left and right censored spells. The probability is "unconditional" in the sense that we do not control for the length of the spell (duration into poverty or "non-poverty"). The only condition that we need to set in order to calculate these probabilities is to demand that the individual is present in the panel for two consecutive waves. The results of the unconditional entry and exit rates into and out of poverty are presented in Table 4 . The probability of exiting poverty in $t$ while being poor in $t-1$ takes its highest values in the Netherlands and Denmark (46.2\% and $44.5 \%$, respectively), while the highest probabilities of entering poverty in $t$ while being non-poor in $t-1$ are reported in Spain (9.5\%), Greece (9.4\%) and Ireland (9.2\%). What is particular interesting about Spain is that it presents high probabilities both for entering and exiting poverty. This can be interpreted as high mobility over and under the poverty line and is in accordance with the previous results that show a high proportion of recurrent poverty in this country. Another, interesting case is Luxembourg. Although, Luxembourg's annual entry rate into poverty is the lowest in the EU, its annual exit rate is also low (the second lowest). This means that while the probability of entering poverty in Luxembourg is low, the probability of exiting poverty is also small in comparison to the other EU countries. This explains the relatively high percentage of permanent poverty that we identified for Luxembourg in the previous results. Finally, when considering the EU as a whole, if we randomly select an individual from the sample who is poor in $t-1$, the probability of finding him poor in $t$ is $35.3 \%$. At the same time, the probability that an individual will enter poverty in $t$, while being non-poor in $t-1$ is less than $7 \%$.

The unconditional probabilities offer a general picture of the entry and exit rates into and out of poverty, but do not control for the duration of the spell or other individual characteristics which may differentiate the probability of an individual with respect to the beginning or ending of a poverty spell. How the hazard rate differs according to the individual, household or other characteristics is analysed in the following section, where multivariate analysis techniques are used. Yet, we are also interested in investigating how the time into 
poverty affects the probability of escaping poverty through the calculation of the conditional to the duration of poverty exit probabilities.

Table 5 shows by country the probability $(* 100)$ of exiting poverty after being poor for one, two, or three years, as well as the cumulative percentage of individuals remaining poor for two, three or more than four years. The individual needs to be present for five consecutive years, so as to be included in the analysis (first year non-poor, second year poor and, then, exit poverty after one, two or three years). In this way, the left-censored cases have been excluded by definition.

In Table 5, the first row presents, for each country, the exit rate as a proportion to the number of individuals at risk of exiting poverty, while the percentage in the second row expresses the proportion of exits to the number of remaining poor at the beginning of each period. The estimates of the second row show that the probability of escaping poverty diminishes as the number of years increases and specifically that it declines more quickly between the first and the second year, than between the second and the third. The exceptions are Denmark and Ireland where the probability of escaping poverty in the third year is almost the same as in the second year. In all the other countries the probability in the third year is lower, and, indeed, substantially lower in Austria, Germany, Luxembourg and Greece, suggesting that the longer the poverty lasts, the harder it is to escape poverty. One explanation for this is related to the idea that poverty is a "self-generating" phenomenon since, for example, it may lead to a deterioration of the "human capital" of the poor and a subsequent decrease in their employment chances. According to this view, a "state dependence" situation is being developed which does not allow the individuals to escape from the vicious poverty circle. Nevertheless, observed or unobserved socio-demographic characteristics may be behind the negative correlation between poverty duration and probability of exiting poverty. In other words, the group of people that remain longer into poverty may possess certain characteristics (observable or unobservable) that obstruct the end of the poverty spell and, thus, poverty may be unrelated to the duration of the poverty spell. If this is the case, the relationship observed between poverty duration and exit probability is spurious and indirectly reflects other causalities.

When we control for the length of spell, $53.1 \%$ of all individuals entering a poverty spell in the EU, escape from it within the first year. In the Netherlands, the probability of exiting within the first year is far higher than in the other EU countries. This is in accordance with the previous results, which show that a high proportion of poverty in the Netherlands is transient poverty. Within the first two years, more than $65 \%$ of the poor escape poverty in all the EU countries, apart from Finland. In fact, Finland has the largest proportion of poor individuals not exiting even after the third year (34.3\%). Yet, because the poverty rate is low in Finland compared to other EU countries, this figure corresponds to less than 3\% of the total Finnish population. Thus, in Finland while the chances of being poor at first place are low, the chances of escaping poverty while being poor are also low. The same is observed in Luxembourg, to a lesser extent. Finally, from the countries that have high poverty rates, the most interesting case is Spain, where $73.6 \%$ of the poor escape poverty within the first two years. Yet, as already demonstrated, in Spain, a large proportion of poverty is recurrent.

Complementary to the examination of conditional exit probabilities is the examination of re-entry rates into poverty. Stevens (1994) was the first to underline the importance of repeated episodes of poverty. In her dynamic analysis of poverty in the United States from 1970 to 1987, using the Panel Study of Income Dynamics, she finds that half of the individuals that escape from poverty fall again below the poverty line within the next five years. Thus, she concludes that exits from single spells do not often imply permanent transitions out of poverty, since poverty may be recurrent. For calculating the re-entry probabilities, we first select all the individuals that are present for five consecutive years and are poor in the first observation year, and non-poor in the second period. Then we examine if the individual re-enters poverty after one, two or three years. The results are reported in Table 6.

As expected, Table 6 demonstrates that duration dependence also exists for poverty reentries: the longer an individual remains out of poverty the less likely it is to re-enter poverty. 
Poor individuals in Spain have the highest probability of returning into poverty after the first year of being non-poor (35.1\%). In Spain and Ireland, almost $50 \%$ of the poor individuals reenter poverty, within the first two years following the poverty exit. Finland has a very high reentry rate in the third year that brings the country into the worse position when summing up all the re-entry rates (only $37.8 \%$ of the individuals under examination do not re-enter poverty after the third year). However, since Finland is present for only five waves in the ECHP, the sample size for calculating these probabilities is small relative to the other countries as well as cohort specific, ${ }^{14}$ therefore the results should be interpreted with care. In Denmark and Austria more than $60 \%$ of the "poor" population examined remains non-poor after the third year following the end of their last poverty spell. To sum up, the re-entry rates in most EU countries are high. Almost $27 \%$ of the poor escaping poverty in year $t$, re-enter poverty in year $t+1$, while another $13 \%$ returns into poverty in year $t+2$. By the third year of observation, almost $50 \%$ of the poor in year $t$ re-enter poverty.

Both the unconditional and the conditional exit and entry (re-entry) rates have been tested for their sensitivity using a four and seven years balanced panel instead of the unbalanced panel. The probabilities do not differ by more than $2 \%$ when the two different datasets are used, implying that most probably attrition does not bias the poverty entry and exit rates substantially at least as far as the lower part of the distribution in concerned. ${ }^{15}$

\section{MULTIVARIATE HAZARD LOGISTIC REGRESSION OF POVERTY EXITS AND ENTRIES (RE-ENTRIES)}

The spell analysis presented in the previous section shows that in all 14 EU MemberStates examined, the probability of exiting poverty is inversely related to the duration of the poverty spell. In other words, an individual has the highest chances to exit poverty in the year following the first year of the poverty spell. The relevant probability decreases sharply in the following years. This phenomenon is known as "duration dependence" or "state dependence", in the sense that the experience of poverty in one year per se raises the risk of being poor also in the next year and, consequently, decreases the "risk" of exiting poverty. This section aims to examine whether this phenomenon is genuine or can be attributed to the presence of other observed or unobserved characteristics of the households and individuals which make certain people more vulnerable to long-term poverty than others. The model used is the discrete time hazard model, presented in section 2, in which the dependent variable is the logit transformation of the hazard rate of poverty exit or entry (re-entry). The results are reported as odds ratios and the relevant probabilities have been estimated for specific results.

Two model specifications are examined. In the first specification, only the five time dummies - one for each time period - are included in the regression, so as to check how the probability of exiting poverty evolves with time when both the observed and unobserved heterogeneity of individuals are not taken into account. The second specification includes both state and change (event variables). The state variables are both time-varying and time-constant and concern the household head (age, gender, educational level, citizenship status) and the household (existence of dependent children ${ }^{16}$ and presence of disable individuals in the household $)^{17}$. The event variables are divided into three groups. The first group concerns the variables that are related to changes in the employment status of household members and

\footnotetext{
${ }^{14}$ It is cohort specific because practically only the cohort that escapes poverty in 1997 is studied.

${ }^{15}$ The results using the balanced panel are available from the authors on request.

${ }^{16}$ The analysis has also been performed using nine different household dummies. Yet, the reduced form of the specification was preferred, given that the two specifications had the same explanatory power.

${ }^{17}$ Various model specifications have been tested that included a larger number of state variables. However, we have decided to exclude the state variables that might cause endogeneity bias (e.g. employment status of the household head, existence of unemployed household members in the household) since also employment change variables are included in the regression. Finally, all specification have been tested with and without controlling for unobserved heterogeneity.
} 
specifically transitions from employment to unemployment or inactivity. The second group concerns individuals that have changed household from one wave to the next. More specifically, the variables describe the events that may have occurred and forced the individual to change household (divorce, union or child leaving parental household). The third group of event variables includes all demographic events that take place, while the individual lives into the same household as in the last wave (death of the household head, divorce of the household head, union of the household head, member moving in/out, death of a household member, birth of a baby, a child reaching the age of 14). The time effect (state dependence) is captured through five time dummies, one for each period at risk of exiting or re-entering poverty. These time dummies do not correspond to the same wave for all individuals. Individuals might exit or (reenter) poverty at different time periods or do not exit or (re-enter) at all within the observation period (right-censored cases) or even attrite from the survey (right truncated cases).

\subsection{Poverty exits}

Tables 7 and $\underline{8}$ present the results for the two specifications described above for transitions out of poverty, controlling for the unobserved heterogeneity across individuals. The first five variables in both tables refer to the time effect and report the probability of exiting poverty after being poor for $t$ years, divided by the probability of not-exiting in that period (odds ratio). When the odds ratio is greater than 1 , the probability of exiting in $t$ (numerator) is greater than the probability of not exiting in $t$, thus exiting in a later wave or not exiting at all (denominator), the opposite holds for odds ratio lower than 1. When the odds ratio approximates 1 , the probability of exiting poverty in $t$ equals the probability of not exiting poverty in $t$.

The results of top panel of Table 7 indicate that in all Member-States, there is significant state dependence, in the sense that as time passes the probability of exiting poverty declines. More specifically, the probability of exiting poverty in the first year is higher than the probability of not exiting in the first year, in Denmark (1.53), the Netherlands (1.48), Austria (1.27), Germany (1.27), Belgium (1.24), and Spain (1.12). On the contrary, the relevant odds ratios are significantly below 1 in Portugal (0.79), Greece (0.87) and the UK (0.88), implying that in these three countries the probability of staying in poverty at least two years is greater than the probability of having only an one year poverty spell. In the second period, the odds ratios fall below 1 in all countries and below 0.50 in Portugal (0.40) and Ireland (0.39). In the following periods, the odds ratios decline further. The predicted probabilities calculated from the estimated coefficients of this specification are reported in the lower panel of Table 7. For most countries, the estimated probabilities equal the conditional exit rates that were calculated directly from the sample in the descriptive statistics (see Table 5). Portugal, Greece and the UK have the lowest predicted exit rates $(0.44,0.47,0.47$ respectively) after being poor for one year. The highest probability of exiting poverty within one year is 0.60 in Denmark and the Netherlands.

In the second specification (Table 8), certain socioeconomic characteristics for the household head and the household are included in the model, as well as a number of "change" variables that capture certain events that might have taken place in the household during the last year and might, thus, have affected its chances to escape poverty. ${ }^{18}$ The first five lines report the results related to the time effect. In this specification, in which other variables apart from time dummies are include in the regression, the five coefficients (odds ratios) of the time dummies consist the baseline hazard. The baseline hazard depicts the evolution of the probability of exiting poverty over time for the baseline group. The baseline group consists of individuals that live in a household with a male household head aged 30-64, who is a citizen of the country under examination and has completed secondary education. There are no dependent children in the household and none of the household members has severe disability or chronic disease. Finally, none of the events examined has taken place for this group.

\footnotetext{
${ }^{18} \mathrm{We}$ also ran a model specification with state variables only. The specification with both state and event variables fitted better for most Member-States. The relevant results are available from the authors on request.
} 
The baseline hazard functions (Kaplan Meier) are illustrated in Figure 1A of the Appendix. The relation between the hazard exit or re-entry rate and time is assumed to be the same to all individuals (common baseline hazard). Differences in characteristics among individuals simply shift the common baseline hazard function up or down proportionately (in parallel when the logit hazard scale is used) and that is why the model is called the proportional odds model. ${ }^{19}$ For each value of the predictor in period $j$ there is a postulated value of the logit hazard. For example, as it is illustrated in Figure 2A, for households whose head has completed secondary education, the values of the hazard are those on the orange line function. The yellow and brown lines correspond to individuals living in households with a household head that has completed primary and tertiary education, respectively. Each of these functions has an identical shape and the distance between them is constant in every time period, when the logit hazard is on the y-axis. ${ }^{20}$ The fact that the values of the time-varying predictors may vary over time, but the effect on the logit hazard in each time period is constant, is called the "proportionality assumption". 21

In Table 8, the results for the time effect show that the magnitude of the relevant coefficients has increased (in comparison to specification 1) in all countries with the exception of Austria, Germany, Denmark and Ireland, although the significance has decreased marginally. ${ }^{22}$ This is not surprising, since the baseline group has relatively more "favourable" characteristics than the general population and, thus, greater chances to exit poverty. Nevertheless, when comparing this baseline hazard with the baseline hazard of specification 1, one needs to have in mind that the results are dependent on the selection of the baseline group.

Whenever the effect is statistically significant, young $(<30)$ and old $(>64)$ age of the household head affect negatively the chances to exit poverty. Only in the Netherlands, the effect goes to the opposite direction for elderly-headed households. Female headship appears to decrease the chances of exiting poverty, but the effect is only significant in Ireland, Belgium, Spain and France. Higher education of the household head strongly and significantly increases the chances to exit poverty in most Member-States, with the remarkable exception of Portugal (odds ratio 0.33 ). On the contrary, ceteris paribus, living in a household with a household head that has completed only primary education increases the chances of exiting poverty in comparison with the reference group only in Denmark (1.36), while it has a negative impact in almost all countries. Only in three countries the effect is not significant. The results for household head citizenship are mixed and not significant in many countries. In general, when the household head does not have an EU citizenship, the probability to observe a transition out of poverty for the household members is lower than when the household head is an EU citizen (with the exception of the UK where the relevant odds is very high 5.68). Further, having an EU citizenship other than that of the country of residence clearly increases the chances of exiting poverty as compared to nationals only in France. In the Netherlands, Italy, France, the UK, Greece, Portugal and Spain, families with dependent children have lower chances to exit

\footnotetext{
${ }^{19}$ Under the proportionality assumption, antilogging logit-hazards yields odds profiles that are constant multiples of each other; that is why the model that invokes this assumption about odds is known as the proportional odds model. It should be noted that a discrete-time hazard model based on a logit transformation does not assume proportional hazards but rather proportional odds. It is the complementary log-log transformation that yields a proportional hazard model.

${ }^{20}$ For communicating the results better, in these graphs the "raw hazard" (probabilities) is reported on the y-axis instead of the logit hazard.

${ }^{21}$ However, it is also reasonable to assume that the effect of educational level of the household head on the poverty exit probability varies with time (is stronger in the second period or even stronger in the third). We have also ran the survival analysis relaxing the proportionality assumption by including interactions with time. Howecer, the effect of the time-varying variable ("educational level of the household head") on the hazard rate did not vary so much with time and the results were similar for all the exogenous variables, therefore we decided to adopt the proportionality assumption in our analysis.

${ }^{22}$ All the time dummies for Luxembourg are insignificant, as well as the results for many other variables. Moreover, the Wald-test could not be calculated, possibly meaning or that the number of observations is very low for the particular analysis or that the model specification does not fit the data well. Therefore, the results concerning Luxembourg should be interpreted with care.
} 
poverty than those without dependent children, while the opposite is observed in Denmark, Finland, Austria and Ireland. Families with one or more disabled household members have significantly lower chances to exit poverty in the few countries that the effect is significant with the exception of Finland, where the effect is surprisingly positive, probably due to the impact of the corresponding social benefits.

With respect to the event variables, it is interesting to note that the transition from unemployment to employment of the household head significantly increases the chance to exit poverty in just four counties. The effect is very strong in Portugal (3.76), followed by Belgium (2.11), France (1.73) and Greece (1.70). The transition from inactivity to employment of the household head increases the probability to exit poverty very strongly in Ireland (5.42), Germany (3.13), Italy (2.93), Finland (2.43) and to a lesser extent in the Netherlands (1.72). The results, also, reveal the importance of second income earners, as the coefficients for transitions from unemployment or inactivity to employment for the spouse and other household members are higher than those for the household head in most countries. In Belgium, Denmark, Greece, France, Ireland, the Netherlands and Portugal, it is clearly the employment events of the spouse that increase the probability to exit poverty. The employment events of the other household members, which are usually the offspring of the household head, play a relatively more important role in Austria, Spain, France, Finland and the UK, but the results are significantly positive in almost all the EU countries examined.

For almost all demographic events, when the coefficient is significant the effect on the dependent variable is positive, meaning that the probabilities to exit poverty increases. Very strong results appear in Greece for individuals that change household due to union, implying that the poor individuals that get married and, usually, leave their parental household are very likely to escape poverty. The result is also strong in Finland for individuals that changed household due to divorce. Even the death and divorce of the household head increase the chances of exiting poverty, implying that the effect of the decline in the equivalence scale is greater than the possible decrease in household income.

Finally, the mobility of households members into and out of the household, as well as the death of a household member increase the chances to exit poverty. This positive effect of demographic events on poverty exits might have two interpretations on how the mechanism of an event might actually work. First, the increase in the probability of exiting poverty might be attributed to the event per se or, second, when an event happens there might be unobserved factors e.g. increase in motivation, unification of the family, etc. that actually cause the end of the poverty spell.

As mentioned earlier, most current survival studies examining poverty or unemployment state dependence take into account unobserved heterogeneity in order to test for the robustness of state dependence or to examine if state dependence is fake. This may happen if the state dependence observed in the data may also be attributed, at least partly, to sorting effects (individuals with "favourable" characteristics tend to leave poverty earlier) rather than indicating true state dependence. These favourable characteristics (e.g. willingness to escape poverty, cleverness, capacities, social networks, etc.) are not easily observable and measurable and this is why they are called unobserved heterogeneity or frailty. The individuals that possess these favourable unobserved characteristics, escape poverty more easily and, thus, differ in a systematic way from the individuals that remain poor. In order to control for unobserved heterogeneity or frailty, an individual-specific unobserved characteristic $u$ is added in the logit model. In the current analysis, $u$ is assumed to follow a normal distribution ${ }^{23}$ and is estimated using random effects techniques. The standard deviation of the heterogeneity variance, "sigma_u", and "rho" which is the ratio of the heterogeneity variance to one plus the

${ }^{23}$ A gamma distribution was also tested, but the model did not converge in many countries. 
heterogeneity variance ${ }^{24}$ and in a way indicates how much of the model variance is due to unobserved heterogeneity.

In Table 7, unobserved heterogeneity, as measured by sigma_u and rho is significant at the $0.1 \%$ level of significance in all countries apart from Finland and Luxembourg. ${ }^{25}$. However, its magnitude is very small in all Member-States. Only in Luxembourg and Finland the magnitude is greater than 1 , but in these countries the model specification failed to capture the unobserved heterogeneity. Consequently, it is normal that the unobserved heterogeneity index captures this residual variation. In the second specification (Table 8), unobserved heterogeneity is not significant in Denmark, Greece and Finland and is only significant at 5\% level in Italy and the UK.

Thus, the conclusion to our main question is that there is true state dependence for poor households and individuals, in the sense that the probabilities to exit poverty deteriorate as time passes. This state dependence is robust to the inclusion of both observed and unobserved factors in the model specification.

\subsection{Poverty entries (re-entries)}

Since left-censored cases are excluded from the hazard analysis, poverty entries are practically poverty re-entries. In terms of poverty spells, the individual is in poverty the first period, then he/she exits poverty in the second period and then (up to five periods), we observe whether he/she re-enters poverty. Table 9 presents the results for specification 1 of the model for poverty re-entries. The baseline hazard declines as time passes, in almost all Member-States. This means that duration dependence also exists for poverty re-entries: the longer an individual remains out of poverty the less likely it is to re-enter poverty. Only in Belgium, Denmark, Ireland and Spain the relative hazard increases during the fifth period of the non-poverty spell. The predicted probabilities are very close to the calculated conditional re-entry rates reported in Table 6. In Mediterranean Countries, Ireland and France, the chances of re-entering poverty are higher compared to the other Member-States during all periods. Thus, apart from high poverty rates, there seems to be high poverty recurrence in these countries.

When other variables are added in the regression (Table 10), the negative relation between duration out of poverty and probability to re-enter persists. Nevertheless, the magnitude of the time effect declines. This is expected, since as explained above, the baseline group has relatively "favorable" characteristics and, thus, lower chances to re-enter poverty than the average person at risk of re-entering poverty. State dependence for poverty re-entries is significant at the $0.1 \%$ level in all periods for all countries. The relevant effect for poverty exits was not so robust in all countries. In terms of magnitude, the baseline hazard is now strongest, in Ireland, Austria, Denmark and France, while in the Mediterranean countries the observed characteristics seem to have "absorbed" a large part of the time effect. The Kaplan-Mayer hazard functions are presented in Figure 3A of the Appendix. As in poverty exits, the analysis for poverty re-entries has been carried out under the proportionality assumption, which seems to hold.

Young household headship $(<30)$ appears to affect positively the chances to re-enter poverty only in Portugal (odds ratio 1.48) and Finland (2.21) and negatively in Luxembourg $(0.44)$. For elderly headed-households $(>64)$ the effect is positive in all countries that the effect is significant, meaning that the chances to have another poverty spell increase in this group. It is interesting to note that, while in many countries elderly poverty are high, the corresponding re-

\footnotetext{
${ }^{24} r h o=\frac{(\text { sigma_u })^{2}}{1+(\text { sigma } u)^{2}}$. If the hypothesis that rho is zero cannot be rejected then frailty is unimportant. Yet, in most countries the likelihood ratio test (not reported in the tables) gives statistically significant frailty.

${ }^{25}$ Sample sizes in these two countries are relative small and the examination period is shorter, since Luxembourg jointed the survey one year and Finland two years after the ECHP was launched. Consequently, the four and three time dummies that are only included in the model in these two countries are not jointly significant (the Wald test does not reject the hypothesis that the coefficients are different from zero).
} 
entry probabilities do not seem to be very high and/or statistically significant. This is because, the nature of this analysis is dynamic and only individuals that exit and re-enter poverty form the final outcome. It should be noted at this point that the dynamic analysis loses some aspects that the static analysis reveals. For instance, if the majority of elderly poor individuals are permanently poor and their income does not fluctuate significantly, then the corresponding figure might appear totally insignificant. It is important when drawing policy recommendations to have in mind this drawback of dynamic analysis.

In most Member-States, living in a female-headed household does not differ significantly than living into a male-headed household as far as poverty re-entries are concerned. Only in the UK, female headship increases the chance to re-enter poverty, while in Austria, Luxembourg and Portugal the relevant probabilities decreases. Higher education (of the household head) does not have a significant preventive effect for not re-entering poverty in all countries. The effect is not significant in six countries and highly significant at the $0.1 \%$ level) only in Germany (0.51), the UK (0.46) and Greece (0.40). Primary education increases the risk to re-enter poverty whenever the effect is statistically significant. Only in the UK, the effect seems to be in the opposite direction (0.83). In total, the educational effect for poverty re-entries is not as strong as for poverty exits. Living with a household head that does not have a citizenship of the country where he/she lives, even if he/she has another EU citizenship increases the risk to re-enter poverty whenever the effect is significant. Yet, the effect is significant only for Ireland and Portugal for household heads having other EU citizenship and in Denmark, France, Luxembourg and the Portugal for non-European household heads.

Greece is the only country where the presence of dependent children in the household decreases the chances to exit poverty in comparison to the baseline group, but does not affect poverty re-entries (the effect is not significant). It is interesting to note that in Finland the presence of dependent children in the household increases the chances to exit poverty, but also increases the chances to re-enter poverty. An assumption to be tested is that families with dependent children receive important social benefits while in poverty, but when they exit poverty these benefits stop and the risk to re-enter poverty remains high. The advantage of families with children in Denmark, when transitions into and out of poverty are examined, is again obvious, since Denmark is the only country where the risk to re-enter poverty is lower for families with dependent children than those without dependent children.

Finally, in most Member-States, living in a household with a disabled individual increases the chances to re-enter poverty. It is interesting to note that the corresponding effect for poverty exits was not significant in all countries (in other words, in many Member-States living with a disabled household member does not appear to be an obstacle for exiting poverty), while in Finland, the Netherlands and Italy, it increased the chances to exit poverty. Nevertheless, it seems that these families are vulnerable to re-enter poverty and this should be taken into account when drawing anti-poverty policies.

Unemployment events do not seem to be as important for poverty re-entries as for poverty exits and in many cases (particularly for "other" household members), the effect is negative while a positive effect could be anticipated. For instance, the transition from employment to unemployment or inactivity of "other" household members in Spain and many other countries reduces the risk to re-enter poverty. Yet, this may happen because the income from the main income earner or other sources might have increased and the second income earners do not have to work anymore (or unemployment benefits are relatively high). In other words, when the household exits the poverty spell, the second income earners might stop working and this is falsely related to lower probability of exiting poverty, while in fact the lower risk is simply due to the increase in household income.

Nevertheless, the dynamic analysis reveals that employment events seem to be related more with poverty exits than unemployment events with poverty re-entries for all household members. Yet, it should also be noted that there is a time-inconsistency of the consequences of unemployment events due to the unemployment benefits. Therefore, while the effect on household income of "getting a job" and, thus, on poverty status is immediate, the effect of 
unemployment is not, because the individual might receive unemployment benefits for one or more years depending on the Member-State where he/she lives. In the current analysis, the events are associated with poverty exits and entries if they happen in the same period. Using lagged event variables could be a solution, but multicollinearity may occur due to the large number of event variables and the presence of time dummies in the same specification.

Demographic changes seem to be more important for poverty entries (re-entries) than for poverty exits. Leaving the parental household is the most important event for poverty reentries in Denmark, Finland, Germany, the Netherlands, the UK and France. The corresponding probability reaches $99 \%$ and $93 \%$ in Finland and Denmark, respectively, meaning that children leaving a parental household, that has just exited poverty, will almost certainly re-enter poverty. Moreover, the birth of the baby, the "rise in needs", as well as the mobility of the household members (moving in/out) of the household increase the chances to re-enter poverty in most Member-States where the corresponding effects are statistically significant.

Like poverty exits, the negative relationship between time and the probability to re-enter poverty may be due to sorting effects (individuals with "favourable" characteristics tend not to re-enter poverty) rather than indicating true state dependence. The unobserved effect added to the logistic regression is again assumed to follow a normal distribution ${ }^{26}$ and is estimated using random effects techniques. The unobserved heterogeneity is significant in all countries $(\mathrm{p}<0.001)$ as the likelihood test for rho reveals. Yet, the magnitude of the heterogeneity in the model explained by the unobserved heterogeneity is small.

In conclusion, the results of state dependence for poverty re-entries are robust to the inclusion of the unobserved heterogeneity factor in the model specification. The probability to re-enter poverty decreases as time passes from the end of the last poverty spell, even when controlling for unobserved heterogeneity.

\section{CONCLUSIONS}

The aim of this paper was to investigate the effect of time on poverty transitions; both on poverty exits and entries. The main question to be answered is whether and to what extent the duration of the poverty (non-poverty) spell affects the probability of exiting (re-entering) poverty.

In the first part of the paper, we used spells methodology in order to examine the duration and recurrence of poverty in 14 European countries. In most countries, the prevalence of poverty, which measures the proportion of individuals that experience poverty at least once in the whole survey period to the total population, is almost double than the poverty rate, as measured by the headcount ratio at a specific year. This was a first indication that mobility exists and that for a substantial proportion of the population poverty is a transient situation. Using the "poverty profiles" methodology we examined in another way whether the duration and recurrence of poverty in the EU varies across Member-States. The spell analysis showed that the probability of exiting poverty in the current year, while being poor in the previous year ranges from $30 \%$ to $46 \%$ and takes the highest values in the Netherlands and Denmark, while the probabilities of entering poverty in the current year while being non-poor in the previous year range from $4 \%$ to $9.5 \%$ with the highest values reported in Spain, Greece and Ireland. When the time spent into a poverty (non-poverty) spell is taken into account, or, in other words, when the conditional probabilities are calculated, the probability of escaping (re-entering) poverty diminishes as the number of years increase and, specifically, it declines more quickly between the first and the second year, than between the consecutive years. These results are a first indication that poverty state dependence or duration dependence exists. In other words, poverty may be a self-generating phenomenon.

\footnotetext{
${ }^{26}$ A gamma distribution was also tested, but the model did not converge in many countries, although it converged for more countries than the corresponding model for poverty exits.
} 
In the second part of the paper, a discrete multivariate hazard model or duration model, of which the dependent variable was the logit transformation of the hazard rate, was used. In order to get accurate results of how the duration in/out of poverty is negatively related to the probability of exiting (or re-entering) poverty, left censored cases were excluded from the analysis.

The results of two model specifications were presented, controlling for unobserved heterogeneity. In almost all the 14 EU Member-States examined, the probability of exiting (reentering) poverty was inversely related to the duration of the poverty (non-poverty) spell. The effect was significant even after the inclusion of variables capturing observed heterogeneity (particular socioeconomic characteristics of the household or the household head, and specific employment and demographic events), as well as to the inclusion of a random effects factor capturing the unobserved heterogeneity among individuals. Even when significant unobserved heterogeneity exists in the sample (and this was true in most Member-States), state dependence remains significant. This finding has important policy implications, in the sense that, since true state dependence is indeed significant compared to the individual unobserved heterogeneity, then it is important to break the "vicious circle" of poverty and try to bring individuals out of poverty using income instruments such as social benefits. Yet, since individual heterogeneity seems also to be significant for getting people into poverty or keeping them out of poverty, the importance of other policies such as education, development of personal skills and capacities or other labour market and social policies, must not be underestimated.

Most event variables included in the analysis turned out to be statistically significant in many countries and they highlight the mechanisms that bring individuals into and out of poverty. For instance, the role of second income earners for ending a poverty spell in Austria, Spain, France, Finland and the UK has been clearly demonstrated. In terms of policy, these events may provide good signals in order to target individuals that may be at-risk of experiencing poverty and, thus, entitled to receive social benefits or be the recipients of other sorts of policies aimed to fight poverty. For example, as shown above, in Finland and Denmark children that leave a parental household that has just exited poverty are extremely likely to reenter poverty within the next few years and should be protected accordingly.

Finally, the observed heterogeneity captured by exogenous socio-economic variables at the individual and the household level, is also significant. Some common patterns across Member-States have been identified. For example, in most countries, households headed by young or elderly individuals are at higher risk of not exiting poverty quickly. Moreover, higher education increases the chances to exit poverty and reduces the chances to re-enter poverty in most countries, but the relevant effect is not so strong for poverty re-entries. Apart from some common patterns observed across Member-States, cross-country differences were also identified. For example, poor female-headed household in Ireland have much lower chances to exit poverty as compared to the remaining EU countries, households headed by elderly individuals in the Netherlands have higher chances to exit poverty than households headed by young or middle-aged individuals etc. Such differences should be taken into account when designing antipoverty policies. The reasons behind the divergence of individual countries from the common EU pattern are not always obvious and further research is needed in order to investigate such issues. For instance, why Portugal is the only country where households headed by individuals that have completed higher education, despite their lower poverty rate, once they are in poverty have fewer chances to exit poverty than households headed by secondary education graduates? Or why in Austria, Denmark, Finland and Ireland the existence of dependent children in the household increases the chances to exit poverty?

In conclusion, the main hypothesis tested in this paper that there is a negative relationship between the time spent into (out) of poverty and the probability to exit (re-enter) poverty has been confirmed for all the countries examined and the result is robust to the inclusion of observed and unobserved individual heterogeneity. In other words, the relationship observed between poverty duration and exit or re-entry probability is not spurious. Last but not least, despite the fact that the data used in the paper refer to the late 1990s and the early 2000s, 
the policy implications of the results are likely to be extremely useful for the design of antipoverty policies during the current economic crisis. 


\section{REFERENCES}

Aassve A, Burgess S, Dickson M, Propper C (2006a) Modelling poverty by not modelling poverty: an application of a simultaneous hazards approach to the UK. CASE Discussion Paper Series No.106, Centre for Analysis of Social Exclusion, London School of Economics, London

Aassve A, Burgess S, Propper C, Dickson M (2006b) Employment, family union and childbearing decisions in Great Britain. Journal of the Royal Statistical Society: Series A (Statistics in Society) 169(4):781-804

Abowd J, Card D (1989) On the covariance structure of earnings and hours changes. Econometrica 57(2):411-445

Allison PD (1982) Discrete-time methods for the analysis of event histories. In: Leinhardt S (ed) Sociological methodology. Jossey-Bass Publishers, San Francisco

Antolin P, Dang T-T, Oxley H, Finnie R, Sceviour R (1999) Poverty dynamics in four OECD countries. Economics Department Working Papers No.212, Economics Department, Organisation for Economic Co-operation and Development (OECD), Paris

Bane MJ, Ellwood DT (1986) Slipping into and out of poverty: the dynamics of spells. Journal of Human Resources 21:1-23

Biewen M (2003) Who are the chronic poor? Evidence on the extent and the composition of chronic poverty in Germany. IZA Discussion Paper Series No.779, Institute for the Study of Labor, Bonn

Biewen M (2006) Who are the chronic poor? An econometric analysis of chronic poverty in germany. In: Creedy J, Kalb G (eds) Dynamics of Inequality and Poverty (Research on Economic Inequality, Volume 13). Emerald Group Publishing Limited

Burgess SM, Propper C (1998) An economic model of household income dynamics, with an application to poverty dynamics among American women. CASE Discussion Paper Series No.9, Centre for Analysis of Social Exclusion, London School of Economics, London

Callens M, Croux C (2009) Poverty Dynamics in Europe. International Sociology 24(3):368396

Canto-Sanchez O (1996) Poverty dynamics in Spain: a study of transitions in the late 1990s. Distributional Analysis Research Programme Discussion Papers No.15, Suntory and Toyota International Centres for Economics and Related Disciplines (STICERD), London School of Economics, London

Canto O (2003) Finding out routes to escape poverty: the relevance of demographic vs. labor market events in Spain. Review of Income and Wealth 49(4):569-588

Cappellari L, Jenkins SP (2004) Modelling low income transitions. Journal of Applied Econometrics 19:593-610

Damioli G (2010) How and Why the Dynamics of Poverty Differ Across European Countries. St. Gallen, Switzerland

Debels A, Vandecasteele L (2008) The time lag in annual household-based income measures: assessing and correcting the bias. Review of Income and Wealth 54(1):71-88

Devicienti F (2002) Poverty persistence in Britain: a multivariate analysis using the BHPS, 1991-1997. Journal of Economics-Zeitschrift Fur Nationalokonomie S 9:307-340

Devicienti F, Gualtieri V, Rossi M (2010) The dynamics and persistence of poverty: evidence from Italy. No.173, Collegio Carlo Alberto

Dewilde C (2004) Poverty mobility in the Belgian and British welfare regimes: the impact of demographic and labour market events. Research Group on Poverty, Social Exclusion and the City (OASeS), Department of Sociology, University of Antwerp, Antwerp

Duncan GJ (1984) Years of poverty, years of plenty: the changing economic fortunes of American workers and families. Institute for Social Research, Michigan 
Duncan GJ, Gustafsson B, Hauser R, Schmauss G, Messinger H, Muffels R, Nolan B, Ray J-C (1993) Poverty dynamics in eight countries. Journal of Population Economics 6(3):215234

Duncan GJ, Rodgers W (1991) Has children's poverty become more persistent? American Sociological Review 56(4):538-550

Eurostat (2001) Reference periods. ECHP Documentation No.DocPAN E2/SEP/28/2001, European Commission, Eurostat, Social and Regional Statistics and Geographical Information System Directorate (E), Living Conditions Unit (E-2), Luxembourg

Eurostat (2003a) ECHP UDB construction of variables: from ECHP questions to UDB variables. ECHP Documentation No.DocPAN 167/2003-12, European Commission, Eurostat, Social and Regional Statistics and Geographical Information System Directorate (E), Living Conditions Unit (E-2), Luxembourg

Eurostat (2003b) ECHP UDB manual: waves 1 to 8, survey years 1994-2001. ECHP Documentation No.DocPAN 168/2003-12, European Commission, Eurostat, Social and Regional Statistics and Geographical Information System Directorate (E), Living Conditions Unit (E-2), Luxembourg

Finnie R (2000) Low income (poverty) dynamics in Canada: entry, exit, spell durations, and total time. Working paper No. W-00-7E, Applied Research Branch, Strategic Policy, Human Resources Development Canada, Hull, Quebec

Finnie R, Sweetman A (2003) Poverty dynamics: empirical evidence for Canada. Canadian Journal of Economics 36(2):291-325

Fouarge D (2004) Poverty and subsidiarity in Europe. Edward Elgar, Cheltenham

Fouarge D, Layte R (2005) Welfare regimes and poverty dynamics: the duration and recurrence of poverty spells in Europe. Journal of Social Policy 34(3):407-426

Gardiner K, Hills J (1999) Policy implication of new data on income mobility. The Economic Journal 109(453):F91-F111

Hansen J, Wahlberg R (2004) Poverty persistence in Sweden. IZA Discussion Paper Series No.1209, Institute for the Study of Labor, Bonn

Heckman JJ (1981) Heterogeneity and state dependence. In: Rosen S (ed) Studies in labor markets. Chicago Press, Chicago, Illinois

Heckman JJ, Singer B (1984) A method for minimizing the impact of distributional assumtions in econometric models for duration data. Econometrica 52(2):271-320

Hill M, Jenkins SP (1999) Poverty among british children: chronic or transitory? In: Bradbury B, Jenkins SP, Micklewright J (eds) The dynamics of child poverty in industrialised countries. Cambridge University Press, Cambridge

Honore BE (2002) Non-linear models with panel data. CEMMAP Working Paper No.13, The Institute of Fiscal Studies, London

Huber PJ. (1967) The behaviour of maximum likelihood estimates under non-standard conditions. Paper presented at the Fifth Berkeley Symposium on Mathematical Statistics and Probability, University of California Press, Statistical Laboratory, University of California, California

Jarvis SJ, Jenkins SP (1997) Low income dynamics in 1990s Britain. Fiscal Studies 18(2):123142

Jenkins SP (1995) Easy estimation methods for discrete-time duration models. Oxford Bulletin of Economics and Statistics 57(1):129-138

Jenkins SP (1997) sbe17 Discrete-time proportional hazards regression. Stata Technical Bulletin $39(22-32)$

Jenkins SP (2000) Modelling household income dynamics. Journal of Population Economics 13:529-567

Jenkins SP (2004) Survival analysis (lecture notes). Institute for Social and Economic Research, University of Essex

Jenkins SP, Rigg JA, Devicienti F (2001) The dynamics of poverty in Britain. Research report No.157, Corporate Document Services for the Department for Work and Pensions, 
Great Britain Department for Work and Pensions; University of Essex, Institute for Social and Economic Research

Jenkins SP, Schluter C (2003) Why are child poverty rates higher in Britain than in Germany? A longitudinal perspective. The Journal of Human Resources 38(2):441-462

Kelly PJ, Lim LL-Y (2000) Survival Analysis for Recurrent Event Data: An Application to Childhood Infectious Diseases. Statistics in Medicine 19:13-33

Layte R, Whelan CT (2003) Moving in and out of poverty: the impact of welfare regimes on poverty dynamics in the EU. European Societies 2(30):167-191

Lillard LA, Willis RJ (1978) Dynamic aspects of earnings mobility. Econometrica 46(5):9851012

McKernan S-M, Ratcliffe C (2005) Events That Trigger Poverty Entries and Exits. Social Science Quarterly 86 (supplement):1146-1169

Muffels R, Fouarge D, Dekker R (2000) Longitudinal poverty and income inequality: a comparative panel study for the Netherlands, Germany and the UK. EPAG Working Paper No.1, European Panel Analysis Group, Tilburg

Muffels RJA (2000) Dynamics of poverty and determinants of poverty transitions. Results from the Dutch socioeconomic panel. In: Rose D (ed) Researching social economic change. Routledge, London

Ondrich J, Rhody SE (1999) Multiple spells in the Prentice-Gloeckler-Meyer likelihood with unobserved heterogeneity. Economic Letters 63:139-144

Oxley H, Dang TT, Antolin P (2000) Poverty dynamics in six OECD countries. OECD Economic Studies (30):7-52

Poggi A (2007) Does persistence of social exclusion exist in Spain? Journal of Economic Inequality 5:53-72

Ruggles P, Williams R (1986) Transition in and out of poverty: new data from the survey of income participation. Research Paper, The Urban Institute, Washington

Singer JD, Willett JB (2003) Applied longitudinal data analysis: modeling change and event occurrence. Oxford University Press, Oxford

Stevens AH (1994) The dynamics of poverty spells: updating Bane and Ellwood. American Economic Review, Papers and Proceedings 84:34-37

Stevens AH (1999) Climbing out of poverty, falling back in: measuring the persistence of poverty over multiple spells. Journal of Human Resources 34(3):557-588

Van Kerm P (2002) How much low income turnover is there in Belgium? Journal of Economics-Zeitschrift Fur Nationalokonomie S9:341-363

Van Kerm P (2004) Une evaluation econometrique des flux et hors de la pauvrete en Belgique. In: Doutrellepont r, Mortelmans D, Casman M-T (eds) Onze ans de vie en Belgique: analyses socio-economiques a partir du panel demographie familiale. Academia Press, Gent

Van Leeuwen J, Pannekoek J (2002) To work oneself out of poverty: the Dutch experience 1989-96. Review of Income and Wealth 48(1):127-140

White H (1980) A heteroskedasticity-consistent covariance matrix estimator and a direct test for heteroskedasticity. Econometrica 48(4):817-830

Willett JB, Singer JD (1995) 'It's Déjà Vu All Over Again: Using Multiple-Spell Discrete-Time Survival Analysis. Journal of Educational and Behavioral Statistics 20:41-67 
Table 1: Average headcount ratio and poverty prevalence rate for the period 1994-2000

\begin{tabular}{l|cccc}
\hline & $\begin{array}{c}\text { Average } \\
\text { Ceadcount ratio }\end{array}$ & $\begin{array}{c}\text { Prevalence } \\
\text { poverty rate }\end{array}$ & $\begin{array}{c}\text { Persistent Non- } \\
\text { poor } \\
\text { (1) }\end{array}$ & $\begin{array}{c}\text { (2) } \\
\text { (2)/(1) }\end{array}$ \\
\hline Austria (A) & 12.8 & 27.6 & 72.4 & 2.16 \\
Belgium (B) & 14.7 & 32.1 & 67.9 & 2.19 \\
Germany (D) & 12.5 & 29.3 & 70.7 & 2.35 \\
Denmark (DK) & 11.1 & 27.4 & 72.6 & 2.46 \\
Spain (E) & 19.3 & 38.6 & 61.4 & 2.00 \\
Greece (EL) & 21.2 & 42.3 & 57.7 & 2.00 \\
France (F) & 15.5 & 32.4 & 67.6 & 2.09 \\
Finland (FIN) & 10.6 & 20.8 & 79.2 & 1.95 \\
Italy (I) & 19.4 & 38.1 & 61.9 & 1.97 \\
Ireland (IRL) & 19.5 & 36.6 & 63.4 & 1.88 \\
Luxemburg (L) & 12.1 & 22.6 & 77.4 & 1.87 \\
Netherlands (NL) & 10.5 & 23.8 & 76.2 & 2.27 \\
Portugal (P) & 21.4 & 40.0 & 60.0 & 1.87 \\
United Kingdom (UK) & 19.0 & 42.1 & 57.9 & 2.22 \\
European Union (EU) & 18.8 & 34.5 & 65.5 & 1.84 \\
\hline
\end{tabular}

Notes:

1. Source: ECHP UDB (Dec 2003 - 2nd issue)

2. For Austria and Luxembourg the figures have been calculated for a six-year period 1995-2000, while for Finland for a five-year period 1996-2000.

3. For calculating the EU figures the observations were weighted by grossing-up factor (country population/sample size) in order to take into account the differences in population across Member-States.

Table 2A: Duration of the longest spell in poverty

\begin{tabular}{lrrrrrrrr}
\hline Country & \multicolumn{7}{c}{$\begin{array}{c}\text { Duration of the longest spell in poverty } \\
\text { (in years) }\end{array}$} \\
\hline & $\mathbf{1}$ & $\mathbf{2}$ & $\mathbf{3}$ & $\mathbf{4}$ & $\mathbf{5 / 5 +}$ & $\mathbf{6 / 6 +}$ & $\mathbf{7 +}$ & Total \\
A & 58.5 & 17.9 & 9.8 & 4.4 & 3.4 & 6.1 & & 100.0 \\
B & 53.4 & 19.6 & 9.8 & 6.7 & 3.1 & 2.9 & 4.5 & 100.0 \\
D & 54.2 & 21.3 & 9.7 & 5.1 & 3.8 & 2.0 & 3.9 & 100.0 \\
DK & 64.3 & 17.0 & 9.1 & 4.1 & 2.8 & 1.1 & 1.7 & 100.0 \\
E & 50.5 & 21.1 & 11.7 & 6.6 & 4.3 & 2.1 & 3.7 & 100.0 \\
EL & 45.1 & 21.2 & 12.5 & 7.3 & 3.4 & 2.8 & 7.7 & 100.0 \\
F & 49.2 & 21.5 & 10.6 & 6.8 & 4.3 & 2.4 & 5.2 & 100.0 \\
FIN & 59.8 & 19.2 & 8.7 & 5.2 & 7.1 & & & 100.0 \\
I & 44.7 & 21.0 & 13.3 & 7.5 & 4.9 & 3.1 & 5.4 & 100.0 \\
IRL & 49.6 & 17.9 & 12.7 & 8.3 & 3.3 & 3.8 & 4.5 & 100.0 \\
L & 48.6 & 20.2 & 9.7 & 10.9 & 3.1 & 7.6 & & 100.0 \\
NL & 60.1 & 18.6 & 11.4 & 5.1 & 2.3 & 1.6 & 0.8 & 100.0 \\
P & 44.1 & 16.7 & 11.5 & 10.2 & 5.5 & 3.3 & 8.8 & 100.0 \\
UK & 48.9 & 20.9 & 10.6 & 6.9 & 4.9 & 3.0 & 4.7 & 100.0 \\
EU & 50.0 & 20.7 & 11.2 & 6.6 & 4.4 & 2.7 & 4.6 & 100.0 \\
\hline
\end{tabular}

Notes: See Table 1 
Table 2B: Partition of persons falling below poverty line according to number of years in poverty

\begin{tabular}{lrrrrrrrr}
\hline Country & \multicolumn{7}{c}{ Total Number of Years in Poverty } & \\
\hline & $\mathbf{1}$ & $\mathbf{2}$ & $\mathbf{3}$ & $\mathbf{4}$ & $\mathbf{5}$ & $\mathbf{6}$ & $\mathbf{7}$ & Total \\
A & 51.3 & 18.7 & 12.0 & 7.0 & 5.0 & 6.1 & & 100.0 \\
B & 45.9 & 18.8 & 12.3 & 8.0 & 5.4 & 5.3 & 4.3 & 100.0 \\
D & 48.2 & 21.0 & 11.4 & 6.2 & 5.6 & 3.8 & 3.7 & 100.0 \\
DK & 56.5 & 21.1 & 9.8 & 5.9 & 3.0 & 2.3 & 1.5 & 100.0 \\
E & 40.8 & 21.4 & 13.4 & 9.1 & 7.2 & 4.8 & 3.3 & 100.0 \\
EL & 34.5 & 20.4 & 13.0 & 9.8 & 7.1 & 6.8 & 8.2 & 100.0 \\
F & 41.5 & 20.9 & 12.4 & 8.2 & 6.9 & 4.8 & 5.4 & 100.0 \\
FIN & 53.7 & 22.3 & 10.9 & 6.9 & 6.3 & & & 100.0 \\
I & 35.7 & 19.7 & 13.2 & 10.0 & 8.6 & 7.3 & 5.6 & 100.0 \\
IRL & 40.8 & 18.0 & 13.6 & 12.3 & 5.6 & 5.6 & 4.3 & 100.0 \\
L & 43.5 & 20.7 & 10.1 & 10.8 & 6.8 & 8.1 & & 100.0 \\
NL & 51.7 & 19.7 & 12.6 & 8.5 & 4.1 & 2.7 & 0.8 & 100.0 \\
P & 35.2 & 18.8 & 11.2 & 10.8 & 7.9 & 6.7 & 9.3 & 100.0 \\
UK & 41.8 & 19.1 & 13.0 & 8.9 & 7.7 & 4.8 & 4.7 & 100.0 \\
EU & 42.5 & 20.2 & 12.5 & 8.4 & 6.9 & 5.1 & 4.5 & 100.0 \\
\hline
\end{tabular}

Notes: See Table 1

Table 3A: Poverty occurrence and persistence (as a percentage of the poor population)

\begin{tabular}{lccccc}
\hline Country & $\begin{array}{c}\text { Transient } \\
\text { poor }\end{array}$ & $\begin{array}{c}\text { Mid-term } \\
\text { poor }\end{array}$ & $\begin{array}{c}\text { Recurrent } \\
\text { poor }\end{array}$ & $\begin{array}{c}\text { Long-term } \\
\text { (persistent) } \\
\text { poor }\end{array}$ & Total \\
\hline A & 51.3 & 12.6 & 12.6 & 23.6 & 100.0 \\
B & 45.9 & 12.0 & 15.0 & 27.1 & 100.0 \\
D & 48.2 & 14.5 & 13.5 & 23.8 & 100.0 \\
DK & 56.5 & 12.8 & 13.8 & 16.9 & 100.0 \\
E & 40.8 & 11.7 & 21.0 & 26.6 & 100.0 \\
EL & 34.5 & 12.6 & 17.9 & 35.0 & 100.0 \\
F & 41.5 & 14.4 & 14.7 & 29.4 & 100.0 \\
FIN & 53.7 & 17.0 & 8.9 & 20.5 & 100.0 \\
I & 35.7 & 11.9 & 17.7 & 34.8 & 100.0 \\
IRL & 40.8 & 11.5 & 14.3 & 33.5 & 100.0 \\
L & 43.5 & 15.0 & 10.7 & 30.8 & 100.0 \\
NL & 51.7 & 11.7 & 15.6 & 21.0 & 100.0 \\
P & 35.2 & 11.3 & 14.1 & 39.4 & 100.0 \\
UK & 41.8 & 12.8 & 15.1 & 30.3 & 100.0 \\
EU & 42.5 & 13.0 & 15.7 & 28.8 & 100.0 \\
\hline
\end{tabular}

Notes: See Table 1 
Table 3B: Poverty occurrence and persistence (as a percentage of the total population)

\begin{tabular}{|c|c|c|c|c|c|c|}
\hline Country & Non-poor & $\begin{array}{c}\text { Transient } \\
\text { poor }\end{array}$ & $\begin{array}{l}\text { Mid-term } \\
\text { poor }\end{array}$ & $\begin{array}{l}\text { Recurrent } \\
\text { poor }\end{array}$ & $\begin{array}{c}\text { Long-term } \\
\text { (persistent) } \\
\text { poor }\end{array}$ & Total \\
\hline $\mathbf{A}$ & 72.4 & 14.2 & 3.5 & 3.5 & 6.5 & 100.0 \\
\hline B & 67.9 & 14.8 & 3.8 & 4.8 & 8.7 & 100.0 \\
\hline D & 70.7 & 14.1 & 4.2 & 4.0 & 7.0 & 100.0 \\
\hline DK & 72.6 & 15.5 & 3.5 & 3.8 & 4.6 & 100.0 \\
\hline $\mathbf{E}$ & 61.4 & 15.7 & 4.5 & 8.1 & 10.3 & 100.0 \\
\hline EL & 57.7 & 14.6 & 5.3 & 7.6 & 14.8 & 100.0 \\
\hline $\mathbf{F}$ & 67.6 & 13.5 & 4.7 & 4.8 & 9.5 & 100.0 \\
\hline FIN & 79.2 & 11.2 & 3.5 & 1.9 & 4.3 & 100.0 \\
\hline I & 61.9 & 13.6 & 4.5 & 6.7 & 13.3 & 100.0 \\
\hline IRL & 63.4 & 14.9 & 4.2 & 5.2 & 12.3 & 100.0 \\
\hline $\mathbf{L}$ & 77.4 & 9.8 & 3.4 & 2.4 & 7.0 & 100.0 \\
\hline NL & 76.2 & 12.3 & 2.8 & 3.7 & 5.0 & 100.0 \\
\hline $\mathbf{P}$ & 60.0 & 14.1 & 4.5 & 5.7 & 15.8 & 100.0 \\
\hline UK & 57.9 & 17.6 & 5.4 & 6.3 & 12.8 & 100.0 \\
\hline $\boldsymbol{E U}$ & 65.5 & 14.6 & 4.5 & 5.4 & 9.9 & 100.0 \\
\hline
\end{tabular}

Notes: See Table 1

Table 4: Annual entry and exit rates into/out of poverty

\begin{tabular}{lcc}
\hline Country & Annual exit rate & Annual entry rate \\
\hline A & 38.1 & 5.8 \\
B & 36.9 & 6.5 \\
D & 38.2 & 5.2 \\
DK & 44.5 & 6.2 \\
E & 39.1 & 9.5 \\
EL & 32.1 & 9.4 \\
F & 32.6 & 6.6 \\
FIN & 33.0 & 5.6 \\
I & 33.8 & 8.0 \\
IRL & 31.5 & 9.2 \\
L & 30.4 & 4.2 \\
NL & 46.2 & 5.1 \\
P & 29.7 & 7.8 \\
UK & 34.1 & 8.0 \\
EU & 35.3 & 7.0 \\
Total number of & & \\
individuals at risk of & & 706,259 \\
exiting/entering poverty & 140,831 & \\
\hline
\end{tabular}

Notes: See Table 1 
Table 5: Conditional to the duration of poverty exit probabilities

\begin{tabular}{|c|c|c|c|c|c|c|c|}
\hline \multirow[t]{2}{*}{ Country } & \multicolumn{3}{|c|}{$\begin{array}{l}\text { Annual exit rate from poverty } \\
\text { after \# years of being poor: }\end{array}$} & \multicolumn{4}{|c|}{$\begin{array}{c}\text { Cumulative percentage of individuals } \\
\text { remaining poor for : }\end{array}$} \\
\hline & 1 & 2 & 3 & 1 & 2 & 3 & $4+$ \\
\hline \multirow[t]{2}{*}{$\mathbf{A}$} & 54.4 & 19.7 & 7.0 & 100.0 & 45.6 & 25.8 & 18.8 \\
\hline & 54.4 & 43.3 & 27.2 & & & & \\
\hline \multirow[t]{2}{*}{ B } & 58.4 & 14.7 & 6.3 & 100.0 & 41.6 & 26.9 & 20.7 \\
\hline & 58.4 & 35.3 & 23.3 & & & & \\
\hline \multirow[t]{2}{*}{ D } & 56.9 & 19.8 & 7.1 & 100.0 & 43.1 & 23.3 & 16.2 \\
\hline & 56.9 & 45.9 & 30.6 & & & & \\
\hline \multirow[t]{2}{*}{ DK } & 57.4 & 16.0 & 9.8 & 100.0 & 42.6 & 26.6 & 16.8 \\
\hline & 57.4 & 37.6 & 36.9 & & & & \\
\hline \multirow[t]{2}{*}{$\mathbf{E}$} & 53.8 & 19.9 & 8.8 & 100.0 & 46.3 & 26.4 & 17.6 \\
\hline & 53.8 & 43.0 & 33.2 & & & & \\
\hline \multirow[t]{2}{*}{ EL } & 48.2 & 20.6 & 7.9 & 100.0 & 51.8 & 31.2 & 23.3 \\
\hline & 48.2 & 39.7 & 25.3 & & & & \\
\hline \multirow[t]{2}{*}{$\mathbf{F}$} & 53.0 & 18.3 & 7.4 & 100.0 & 47.0 & 28.7 & 21.3 \\
\hline & 53.0 & 38.9 & 25.9 & & & & \\
\hline \multirow[t]{2}{*}{ FIN } & 44.8 & 12.7 & 8.2 & 100.0 & 55.2 & 42.5 & 34.3 \\
\hline & 44.8 & 23.1 & 19.3 & & & & \\
\hline \multirow[t]{2}{*}{ I } & 54.3 & 16.3 & 7.8 & 100.0 & 45.7 & 29.4 & 21.6 \\
\hline & 54.3 & 35.7 & 26.5 & & & & \\
\hline \multirow[t]{2}{*}{ IRL } & 55.1 & 9.4 & 7.1 & 100.0 & 44.9 & 35.5 & 28.4 \\
\hline & 55.1 & 21.0 & 20.0 & & & & \\
\hline \multirow[t]{2}{*}{$\mathbf{L}$} & 45.7 & 21.3 & 8.0 & 100.0 & 54.3 & 33.0 & 25.0 \\
\hline & 45.7 & 39.2 & 24.3 & & & & \\
\hline \multirow[t]{2}{*}{ NL } & 63.5 & 15.2 & 6.5 & 100.0 & 36.5 & 21.3 & 14.8 \\
\hline & 63.5 & 41.6 & 30.5 & & & & \\
\hline \multirow[t]{2}{*}{$\mathbf{P}$} & 53.5 & 14.2 & 5.7 & 100.0 & 46.6 & 32.3 & 26.7 \\
\hline & 53.5 & 30.5 & 17.5 & & & & \\
\hline \multirow[t]{2}{*}{ UK } & 47.1 & 19.2 & 10.2 & 100.0 & 52.9 & 33.8 & 23.6 \\
\hline & 47.1 & 36.2 & 30.2 & & & & \\
\hline \multirow[t]{2}{*}{$\boldsymbol{E} \boldsymbol{U}$} & 53.1 & 18.3 & 8.1 & 100.0 & 46.9 & 28.7 & 20.5 \\
\hline & 53.1 & 39.0 & 28.4 & & & & \\
\hline
\end{tabular}

Notes:

1. Source: ECHP UDB (Dec 2003 - 2nd issue)

2. For calculating the conditional probabilities, the individuals are present for five consecutive years (first year nonpoor, second year poor and then exit poverty after one, two or three years). The left-censored cases have been excluded by definition. All cases have been weighted using the cross-sectional weights, while the EU figures have been weighted using both the cross-sectional weights and the grossing-up factor (country population/sample size).

3. The first row for each country presents the exit rate as a percentage to the number of individuals at risk of exiting poverty, while the second as a percentage to the number of remaining poor at the start of each period in each country. 
Table 6: Re-entry poverty rates

\begin{tabular}{|c|c|c|c|c|c|c|c|}
\hline \multirow[t]{2}{*}{ Country } & \multicolumn{3}{|c|}{$\begin{array}{l}\text { Annual rate of re-entering poverty } \\
\text { after \# years of being non-poor } \\
\text { following a poverty spell: }\end{array}$} & \multicolumn{4}{|c|}{$\begin{array}{l}\text { Cumulative percentage of individuals } \\
\text { remaining non-poor for: }\end{array}$} \\
\hline & 1 & 2 & 3 & 1 & 2 & 3 & $4+$ \\
\hline \multirow[t]{2}{*}{$\mathbf{A}$} & 20.7 & 13.0 & 6.0 & 100.0 & 79.3 & 66.3 & 60.3 \\
\hline & 20.7 & 16.3 & 9.1 & & & & \\
\hline \multirow[t]{2}{*}{ B } & 22.3 & 15.1 & 8.2 & 100.0 & 77.7 & 62.6 & 54.3 \\
\hline & 22.3 & 19.5 & 13.2 & & & & \\
\hline \multirow[t]{2}{*}{ D } & 20.2 & 10.0 & 6.4 & 100.0 & 79.8 & 69.9 & 63.5 \\
\hline & 20.2 & 12.5 & 9.1 & & & & \\
\hline \multirow[t]{2}{*}{ DK } & 27.6 & 11.7 & 6.9 & 100.0 & 72.5 & 60.8 & 53.9 \\
\hline & 27.6 & 16.2 & 11.4 & & & & \\
\hline \multirow[t]{2}{*}{$\mathbf{E}$} & 35.1 & 13.2 & 7.9 & 100.0 & 64.9 & 51.7 & 43.8 \\
\hline & 35.1 & 20.4 & 15.3 & & & & \\
\hline \multirow[t]{2}{*}{ EL } & 30.2 & 14.1 & 10.2 & 100.0 & 69.8 & 55.7 & 45.5 \\
\hline & 30.2 & 20.2 & 18.2 & & & & \\
\hline \multirow[t]{2}{*}{$\mathbf{F}$} & 26.6 & 15.1 & 8.4 & 100.0 & 73.4 & 58.3 & 50.0 \\
\hline & 26.6 & 20.5 & 14.4 & & & & \\
\hline \multirow[t]{2}{*}{ FIN } & 22.7 & 18.1 & 21.4 & 100.0 & 77.3 & 59.2 & 37.8 \\
\hline & 22.7 & 23.5 & 36.1 & & & & \\
\hline \multirow[t]{2}{*}{ I } & 30.1 & 12.6 & 7.9 & 100.0 & 69.9 & 57.3 & 49.4 \\
\hline & 30.1 & 18.0 & 13.8 & & & & \\
\hline \multirow[t]{2}{*}{ IRL } & 34.3 & 12.6 & 7.7 & 100.0 & 65.7 & 53.1 & 45.5 \\
\hline & 34.3 & 19.2 & 14.4 & & & & \\
\hline \multirow[t]{2}{*}{$\mathbf{L}$} & 20.3 & 14.5 & 8.1 & 100.0 & 79.7 & 65.2 & 57.1 \\
\hline & 20.3 & 18.2 & 12.4 & & & & \\
\hline \multirow[t]{2}{*}{ NL } & 26.6 & 9.5 & 8.7 & 100.0 & 73.4 & 63.9 & 55.2 \\
\hline & 26.6 & 13.0 & 13.6 & & & & \\
\hline \multirow[t]{2}{*}{$\mathbf{P}$} & 24.0 & 12.7 & 11.1 & 100.0 & 76.0 & 63.3 & 52.2 \\
\hline & 24.0 & 16.7 & 17.6 & & & & \\
\hline \multirow[t]{2}{*}{ UK } & 24.5 & 14.8 & 9.0 & 100.0 & 75.5 & 60.7 & 51.8 \\
\hline & 24.5 & 19.6 & 14.8 & & & & \\
\hline \multirow[t]{2}{*}{$E \boldsymbol{U}$} & 26.6 & 12.9 & 8.1 & 100.0 & 73.4 & 60.6 & 52.5 \\
\hline & 26.6 & 17.5 & 13.3 & & & & \\
\hline
\end{tabular}

Notes:

1. Source: ECHP UDB (Dec 2003 - 2nd issue)

2. For calculating the re-entry probabilities, the individuals are present for five consecutive years (first year poor, second year non-poor and then examine if the individual re-enters poverty after one, two or three years). The rightcensored cases have been excluded by definition. All cases have been weighted using the cross-sectional weights, while the EU figures have been weighted using both the cross-sectional weights and the grossing-up factor (country population/sample size).

3. The first row for each country presents the re-entry rate as a percentage to the initial number of individuals at risk of re-entering poverty, while the second as a percentage to the number of individuals remaining non-poor at the start of each period in each country. 


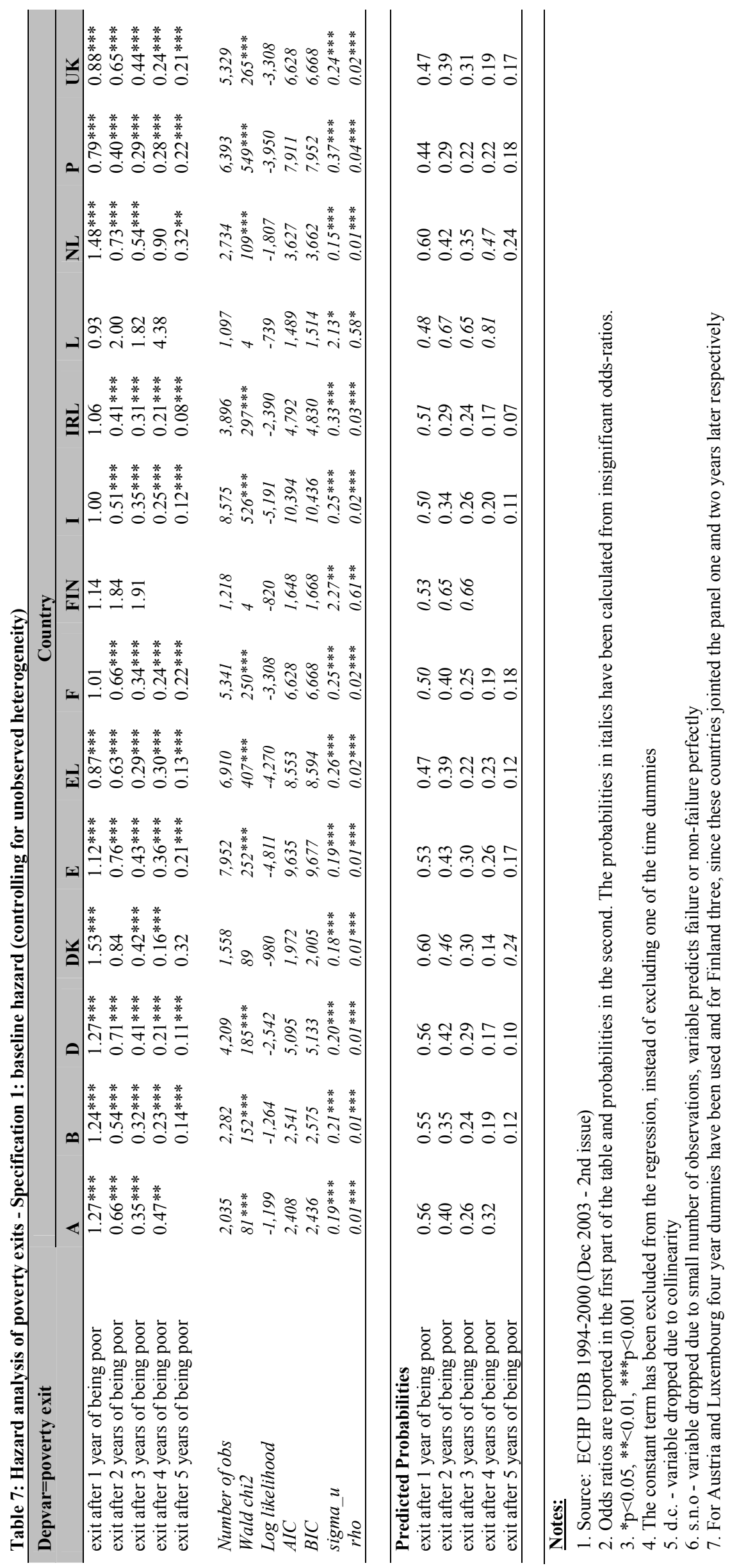




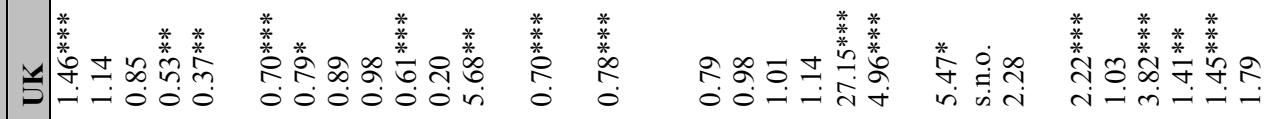

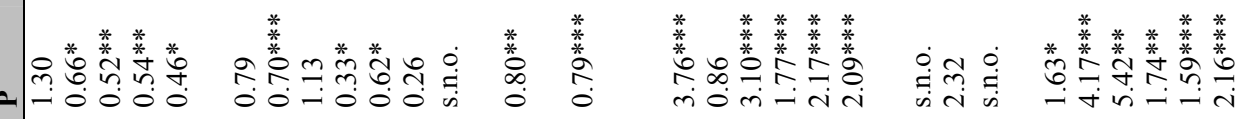
z

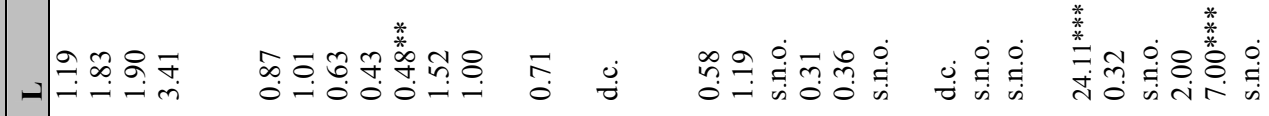

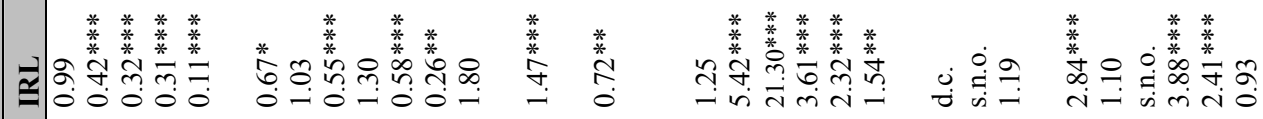

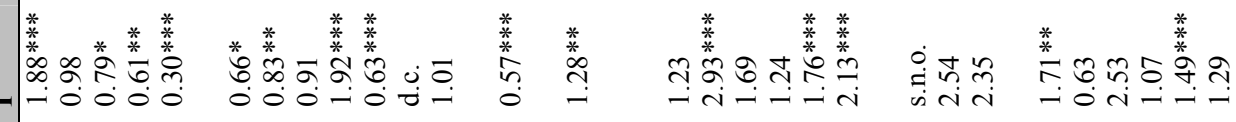
そ)

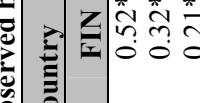

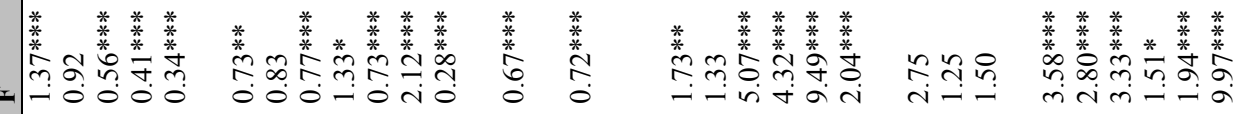

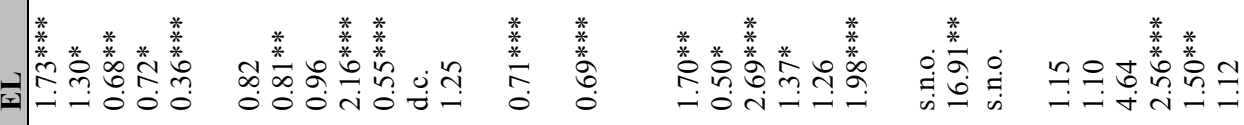

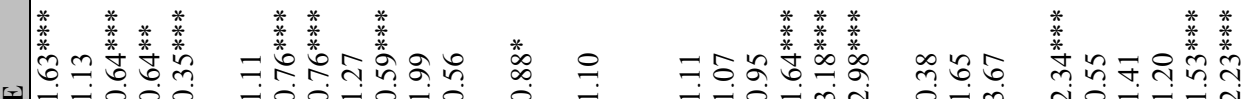

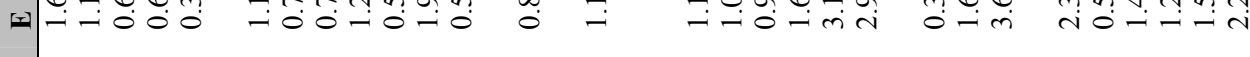

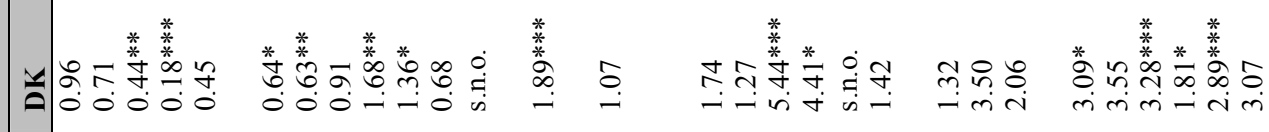
ค

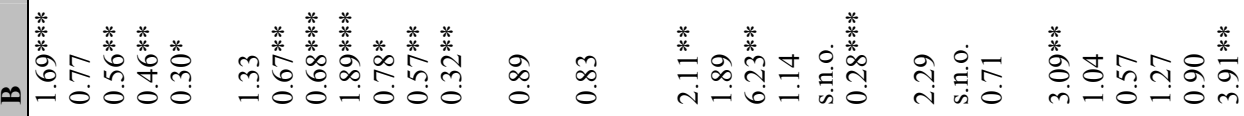

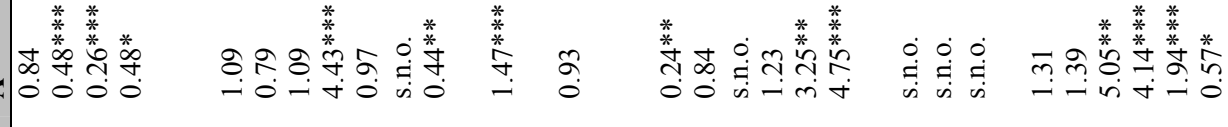

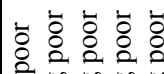

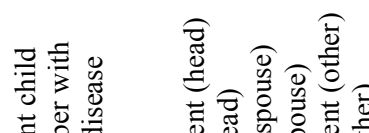

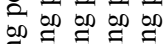
a.

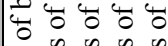

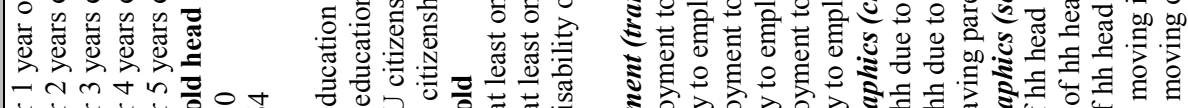

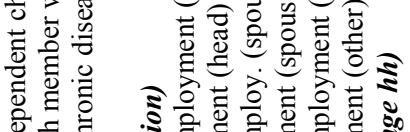

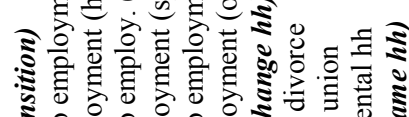

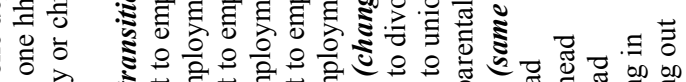

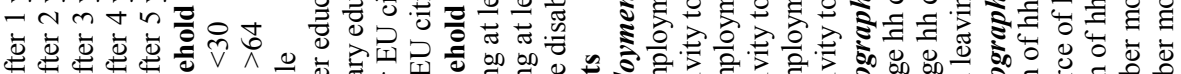

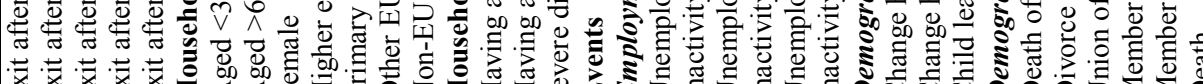




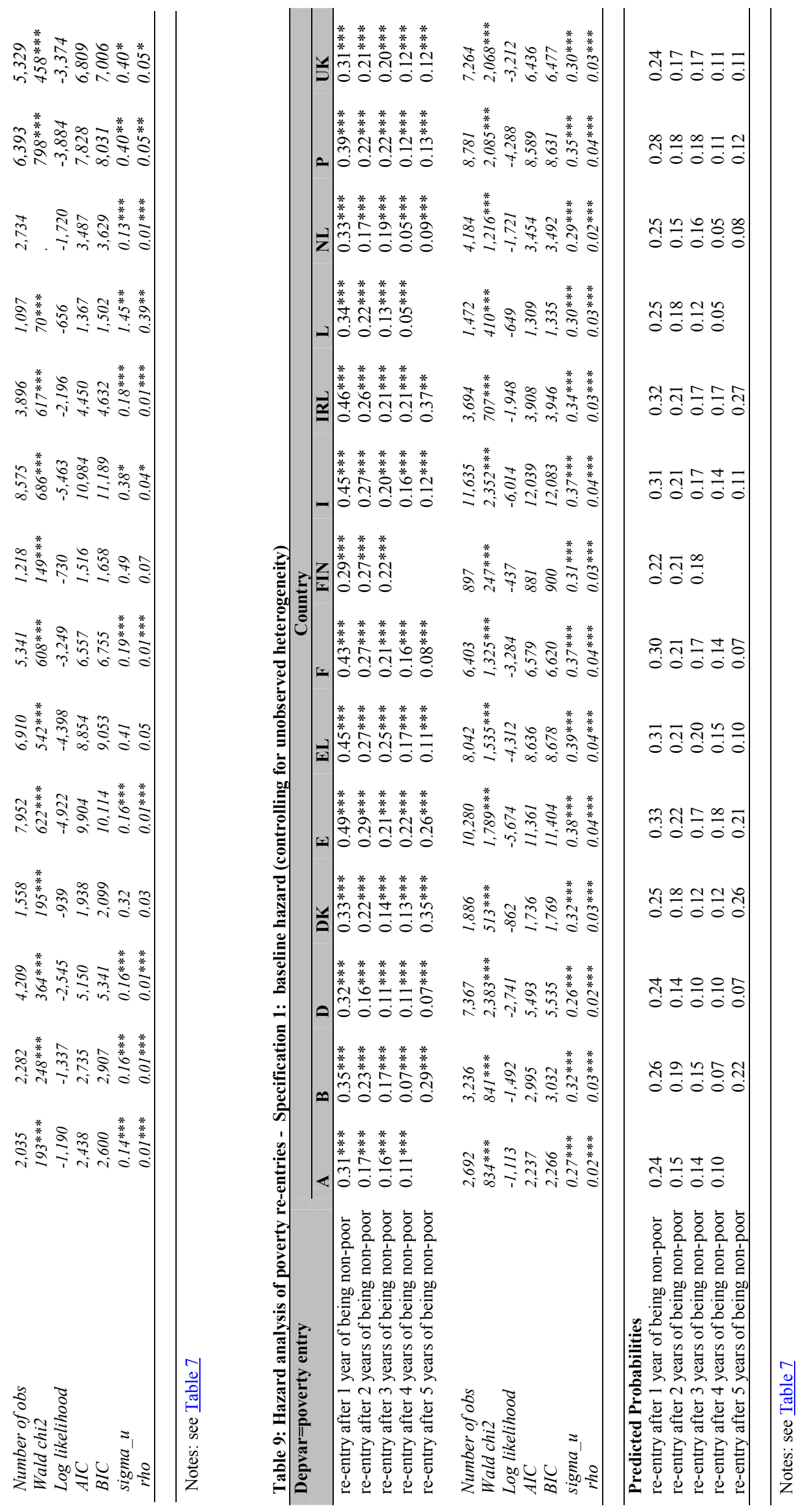




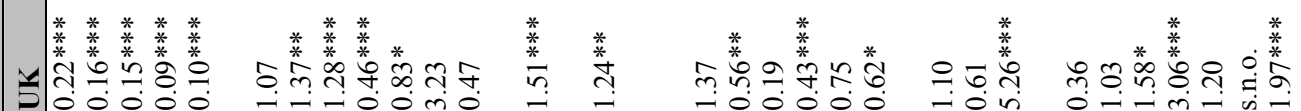

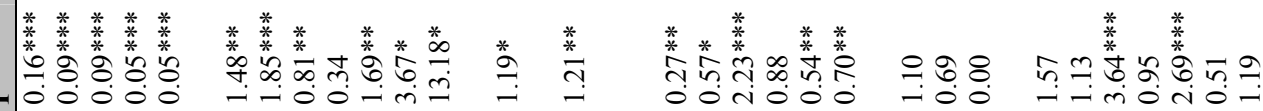

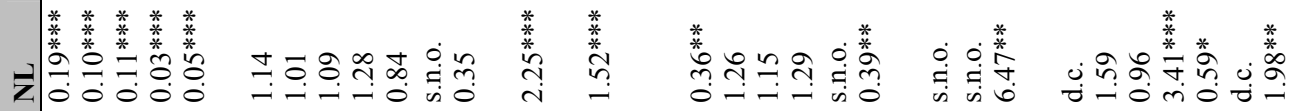

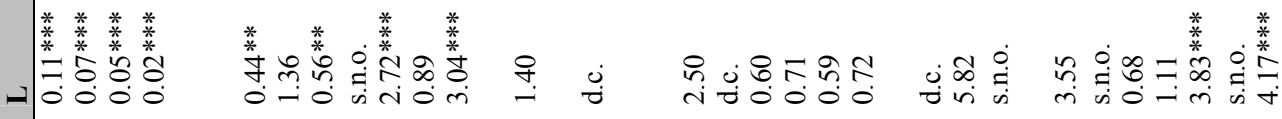

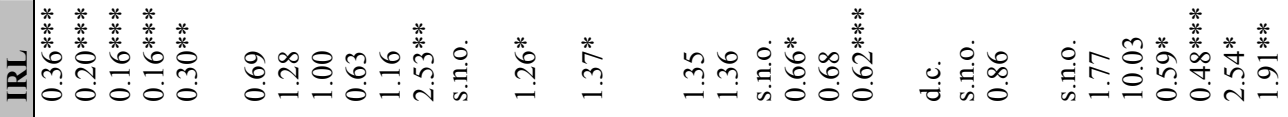

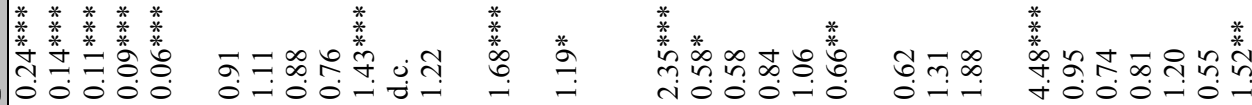

莘莘

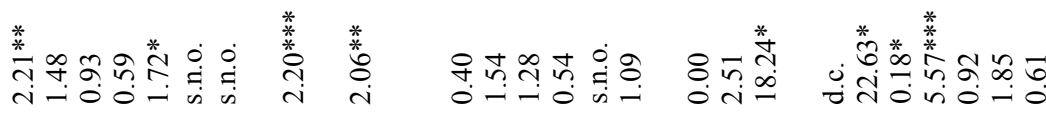

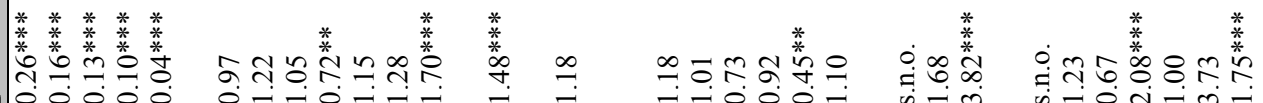

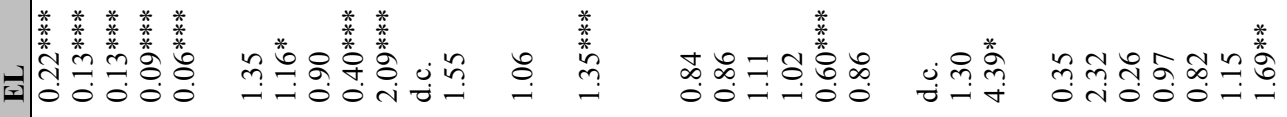

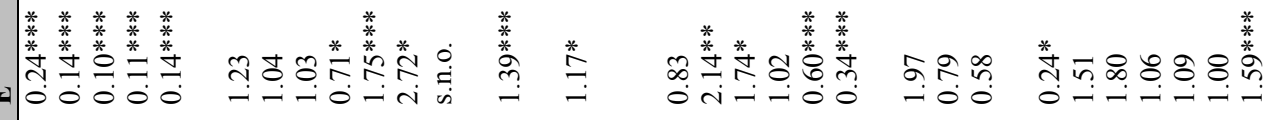

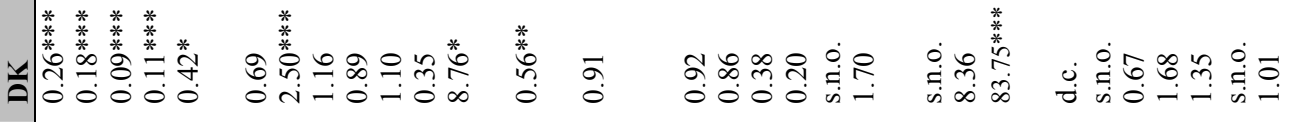

け

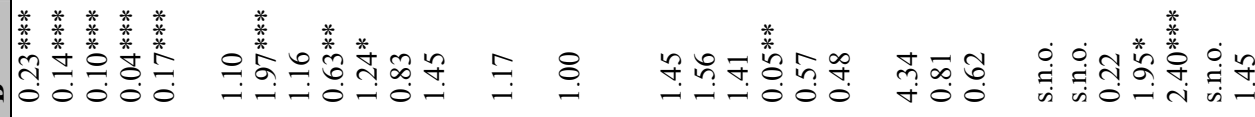

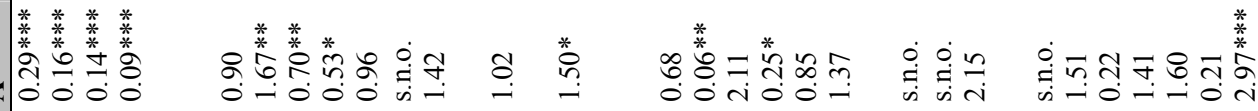

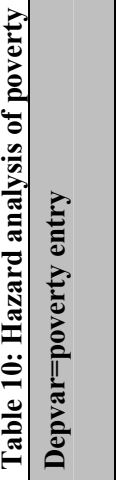

若客客客宫

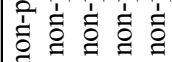

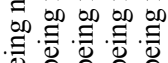

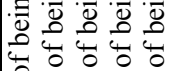

あँ

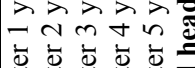

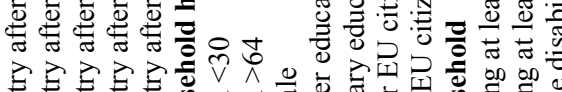

뭉

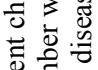

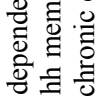

o

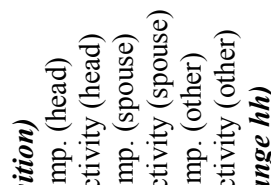

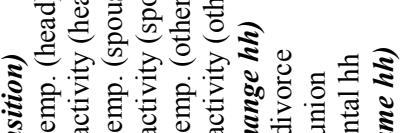

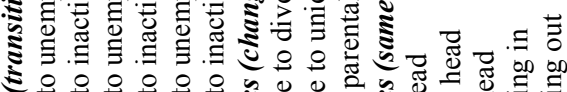

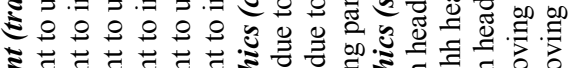

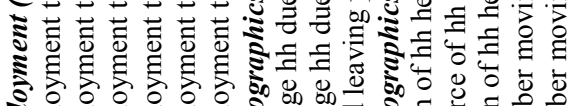

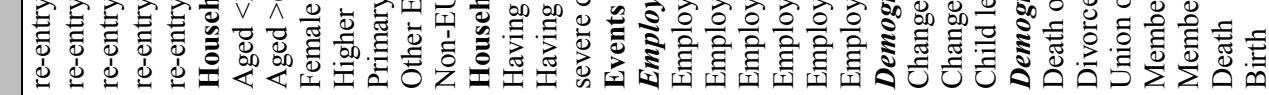




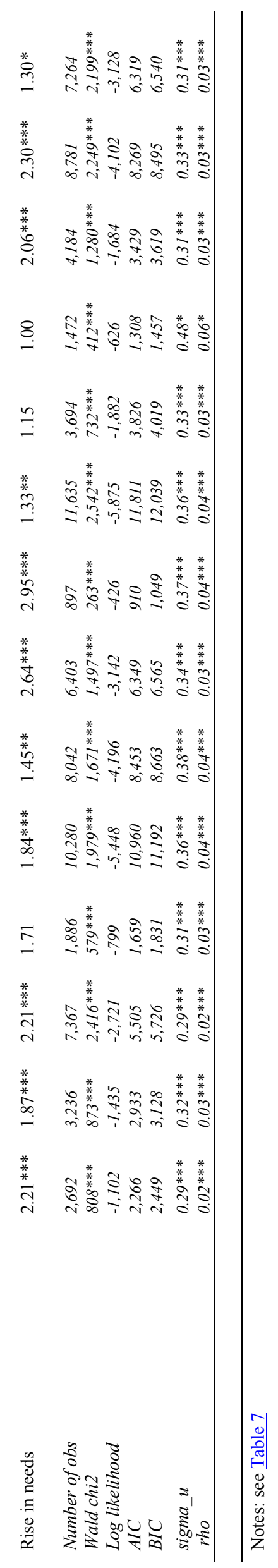




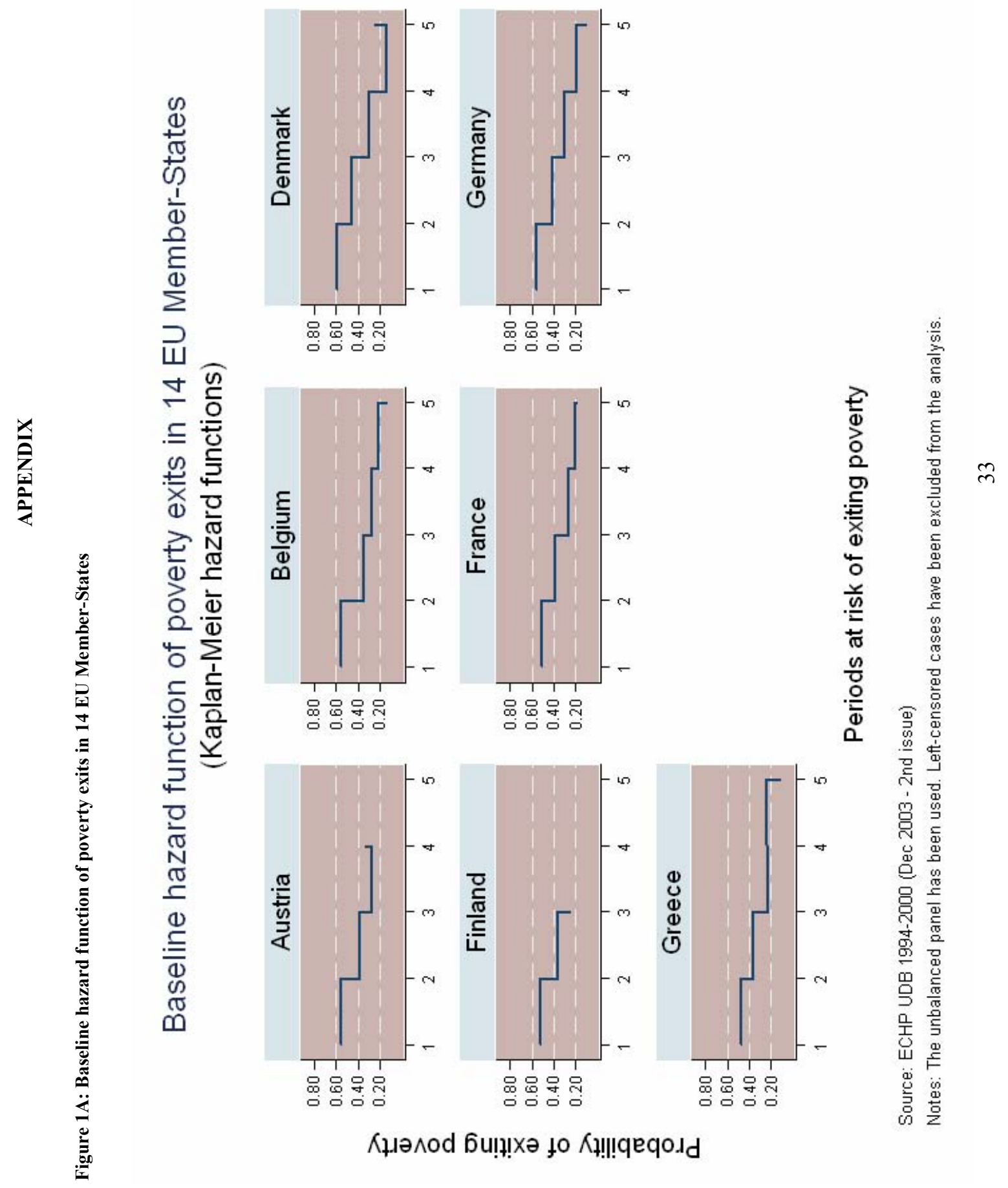




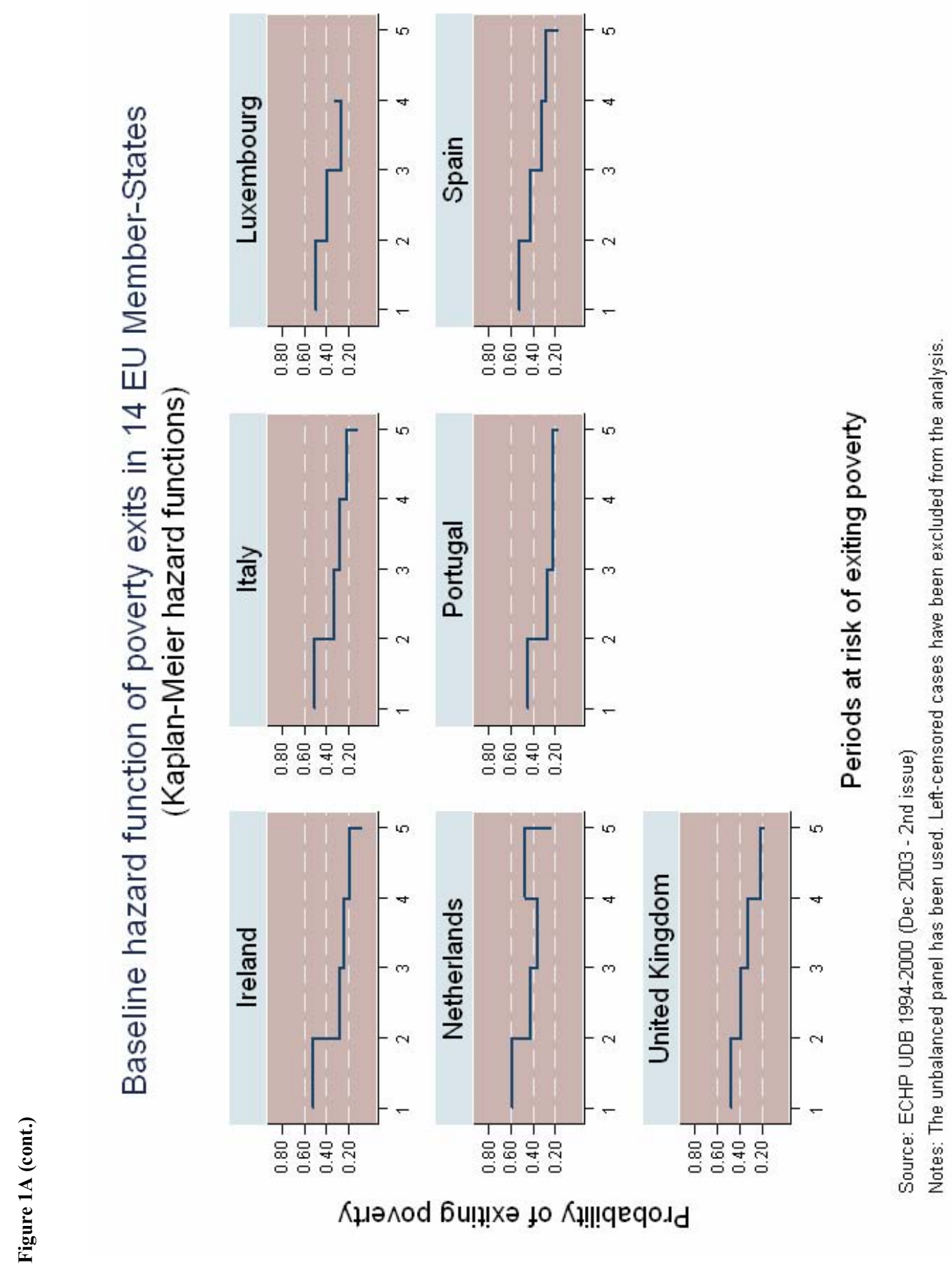




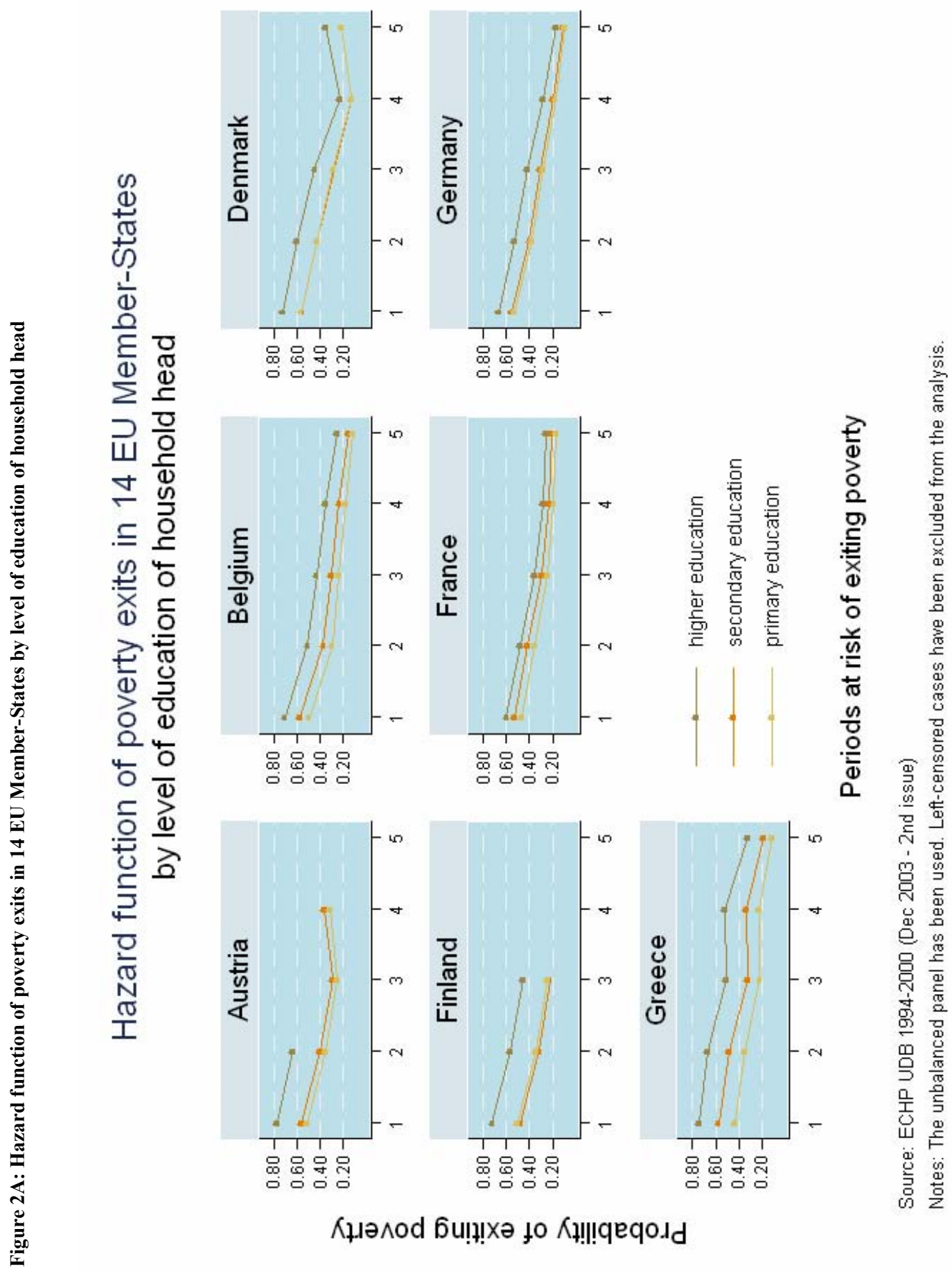

$n$ 


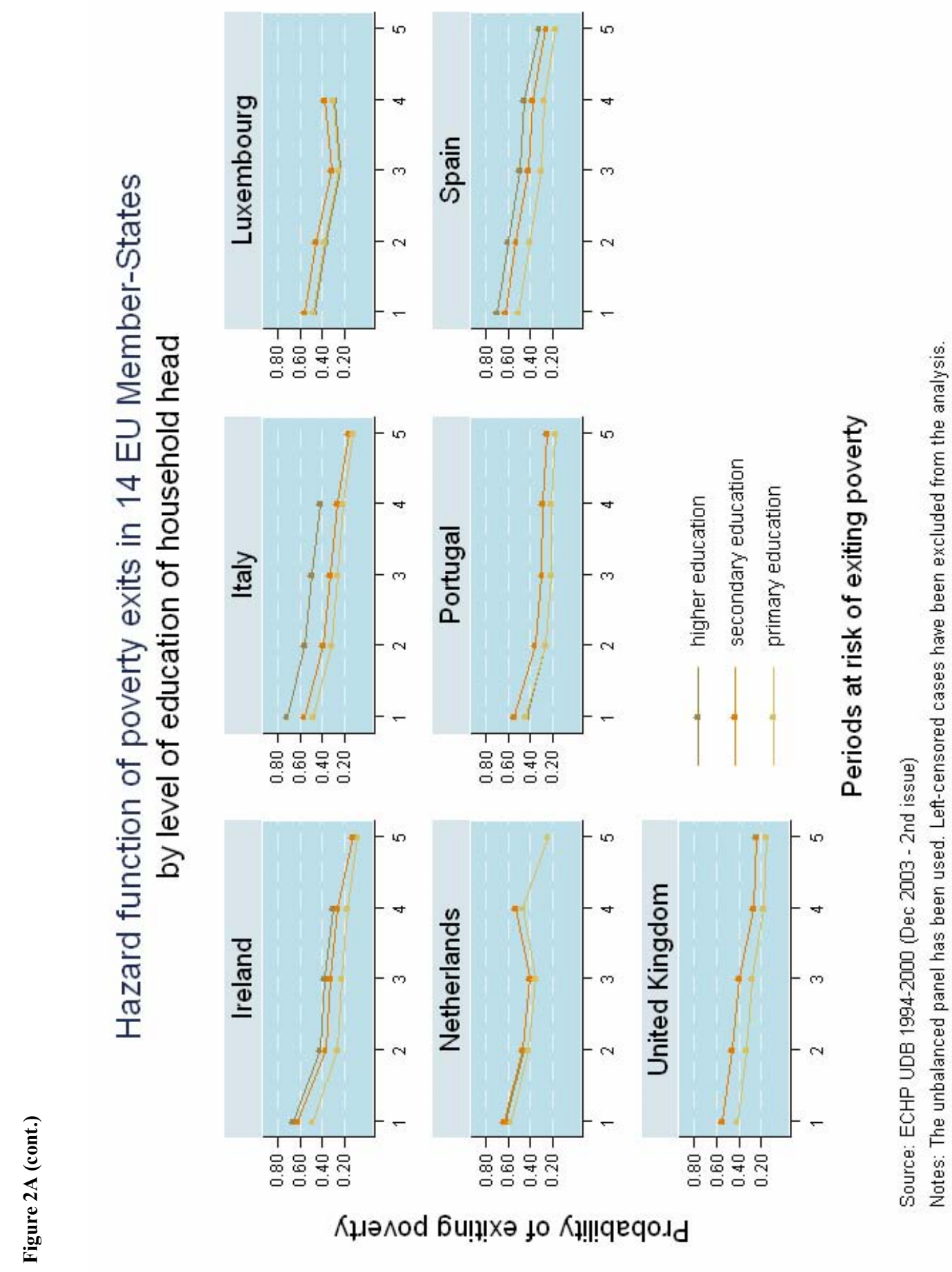




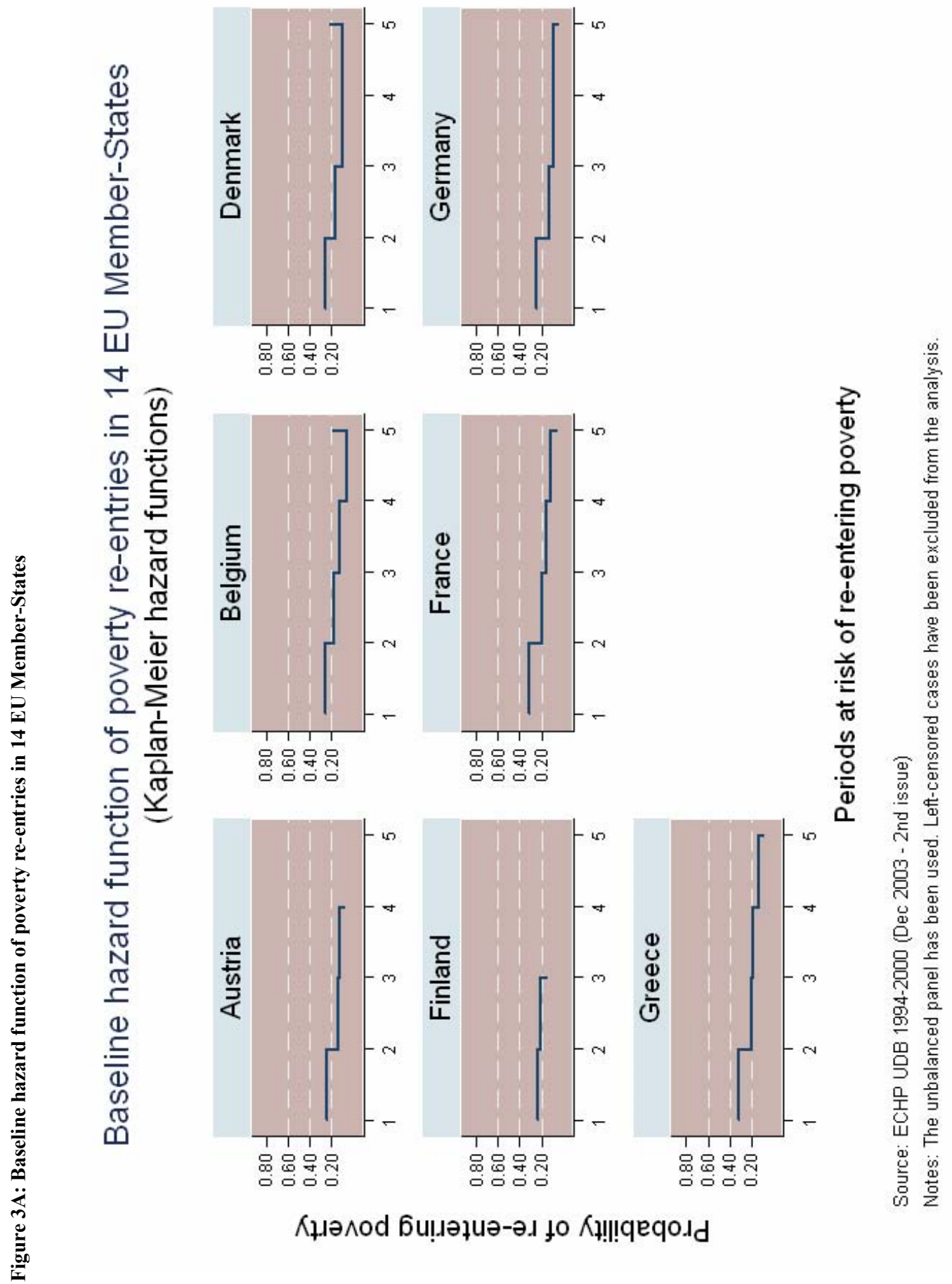




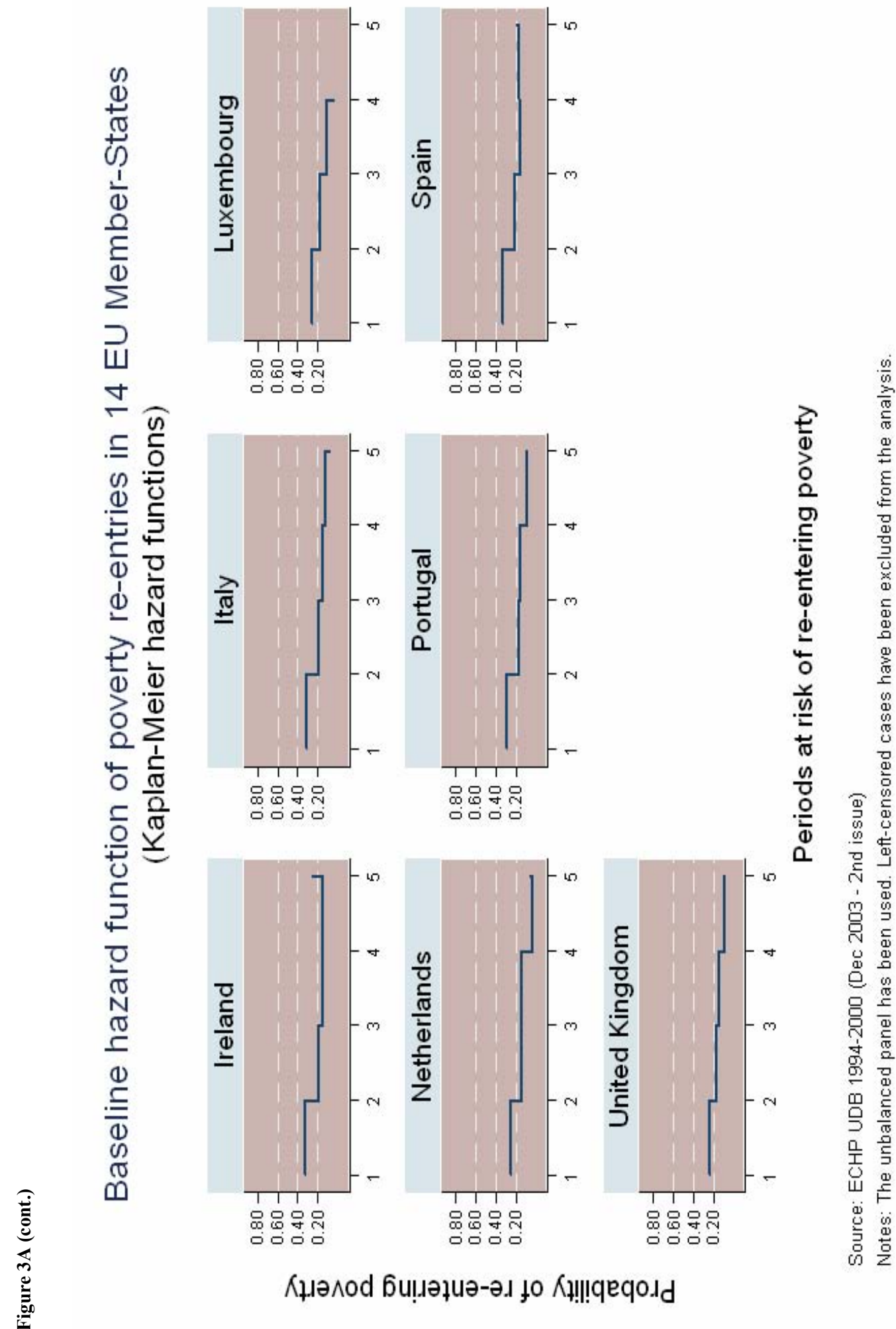

